\title{
A Landsat-based model for retrieving total suspended solids concentration of estuaries and coasts in China
}

\author{
Chongyang Wang ${ }^{1,2,3}$, Shuisen Chen ${ }^{1}$, Dan $\mathbf{L i}^{1}$, Danni Wang ${ }^{4}$, Wei Liu ${ }^{1,2,3}$, and Ji Yang ${ }^{1,2,3}$ \\ ${ }^{1}$ Guangdong Open Laboratory of Geospatial Information Technology and Application, \\ Guangdong Engineering Technology Center for Remote Sensing Big Data Application, \\ Guangdong Key Laboratory of Remote Sensing and GIS Technology Application, \\ Guangzhou Institute of Geography, Guangzhou 510070, China \\ ${ }^{2}$ Guangzhou Institute of Geochemistry, Chinese Academy of Sciences, Guangzhou 510640, China \\ ${ }^{3}$ University of Chinese Academy of Sciences, Beijing 100049, China \\ ${ }^{4}$ Department of Resources and the Urban Planning, Xin Hua College of Sun Yat-Sen University, \\ Guangzhou 510520, China
}

Correspondence to: Shuisen Chen (css@gdas.ac.cn)

Received: 6 December 2016 - Discussion started: 6 April 2017

Revised: 5 September 2017 - Accepted: 17 October 2017 - Published: 30 November 2017

\begin{abstract}
Retrieving total suspended solids (TSS) concentration accurately is essential for sustainable management of estuaries and coasts, which plays a key role in the interaction between hydrosphere, pedosphere and atmosphere. Although many TSS retrieval models have been published, the general inversion method that is applicable to different field conditions is still under research. In order to obtain a TSS remote sensing model that is suitable for estimating TSS concentrations with wide range in estuaries and coasts by Landsat imagery, after reviewing a number of Landsatbased TSS retrieval models and improving a comparatively better one among them, this study developed a quadratic model using the ratio of logarithmic transformation of red band and near-infrared band and logarithmic transformation of TSS concentration (QRLTSS) based on 119 in situ samples collected in 2006-2013 from five regions of China. It was found that the QRLTSS model works well and shows a satisfactory performance. The QRLTSS model based on Landsat TM (Thematic Mapper), ETM+ (Enhanced Thematic Mapper Plus) and OLI (Operational Land Imager) sensors explained about $72 \%$ of the TSS concentration variation (TSS: $4.3-577.2 \mathrm{mgL}^{-1}, N=84, P$ value $<0.001$ ) and had an acceptable validation accuracy (TSS: $4.5-474 \mathrm{mg} \mathrm{L}^{-1}$, root mean squared error (RMSE) $\left.\leq 25 \mathrm{mgL}^{-1}, N=35\right)$. In addition, a threshold method of red-band reflectance (OLI: 0.032, ETM+ and TM: 0.031) was proposed to solve the
\end{abstract}

two-valued issue of the QRLTSS model and to retrieve TSS concentration from Landsat imagery. After a 6S modelbased atmospheric correction of Landsat OLI and ETM+ imagery, the TSS concentrations of three regions (Moyangjiang River estuary, Pearl River estuary and Hanjiang River estuary) in Guangdong Province in China were mapped by the QRLTSS model. The results indicated that TSS concentrations in the three estuaries showed large variation ranging from 0.295 to $370.4 \mathrm{mg} \mathrm{L}^{-1}$. Meanwhile we found that TSS concentrations retrieved from Landsat imagery showed good validation accuracies with the synchronous water samples (TSS: $7-160 \mathrm{mg} \mathrm{L}^{-1}$, RMSE: $11.06 \mathrm{mgL}^{-1}, N=22$ ). The further validation from EO-1 Hyperion imagery also showed good performance (in situ synchronous measurement of TSS: $106-220.7 \mathrm{mg} \mathrm{L}^{-1}$, RMSE: $26.66 \mathrm{mg} \mathrm{L}^{-1}, N=13$ ) of the QRLTSS model for the area of high TSS concentrations in the Lingding Bay of the Pearl River estuary. Evidently, the QRLTSS model is potentially applied to simulate high-dynamic TSS concentrations of other estuaries and coasts by Landsat imagery, improving the understanding of the spatial and temporal variation of TSS concentrations on regional and global scales. Furthermore, the QRLTSS model can be optimized to establish a regional or unified TSS retrieval model of estuaries and coasts in the world for different satellite sensors with medium- and high-resolution similar to Landsat TM, ETM+ and OLI sensors or with similar 
red bands and near-infrared bands, such as ALI, HJ-1 A and B, LISS, CBERS, ASTER, ALOS, RapidEye, Kanopus-V, and GF.

\section{Introduction}

The amount of total suspended solids (TSS) is a critical factor of the ecological environment of water bodies, which directly and deeply affects their optical properties through absorbing and scattering of the sunlight (Chen et al., 2015b; Pozdnyakov et al., 2005; Wang et al., 2016; Wu et al., 2013), leading to impacts on the primary production of the water areas (May et al., 2003). Estuaries and coasts are the most important intermediate zones that connect hydrosphere, pedosphere and atmosphere, which then pass on a deep and wide impact on many aspects of our societal and natural environment (Nechad et al., 2010; Pozdnyakov et al., 2005). The topics of TSS concentration monitoring and spatial and temporal variation assessment have been paid great attention, and the associated research work has been conducted frequently by a variety of scholars, government branches and society communities (Caballero et al., 2014; Giardino et al., 2015; Liu et al., 2003; Lu et al., 2012; Montanher et al., 2014; Nechad et al., 2010; Olmanson et al., 2013; Pozdnyakov et al., 2005; Rao et al., 2009; Shen et al., 2008; Tang et al., 2004b; Zhang et al., 2007). Many methods can be used to estimate TSS concentrations of water bodies, including hydrologicalsite monitoring, in situ investigation, physical models, numerical simulation, remote sensing and so on (Chen et al., 2015a). Retrieving TSS concentrations from remote sensing data has unique advantages due to the wide spatial coverage and periodic revisit, such as the Land Observation Satellite (Landsat), the Earth-Observing One satellite (EO-1), the Moderate Resolution Imaging Spectroradiometer (MODIS), the Medium Resolution Imaging Spectrometer (MERIS), the Geostationary Ocean Color Imager (GOCI), the Sea Viewing Wide Field of View Sensor (SeaWiFS), Systeme Probatoire d'Observation dela Tarre (SPOT) and the Environment and Disaster Monitoring and Forecasting Small Satellite Constellation $(\mathrm{HJ})$. Compared to other remote sensing data, the Landsat series of imagery has an advantage in spatiotemporal dynamics analysis of TSS concentrations (Wu et al., 2013) due to the additional good quality, high spatial resolution and inheritance, especially long-term historical data since 1972.

Many Landsat-based models have estimated the TSS concentration with empirical, semiempirical, semianalytical or analytical algorithms (Chen et al., 2014; Doxaran et al., 2003; Fraser, 1998; Islam et al., 2001; Li et al., 2010; Montanher et al., 2014; Nas et al., 2010; Oyama et al., 2009; Raharimahefa and Kusky, 2010; Rao et al., 2009; Ritchie and Cooper, 1991; Topliss et al., 1990; Volpe et al., 2011; Wang et al., 2016; Wu et al., 2013; Zhang et al., 2014). Based on the rigorous theoretical derivation, the semianalytical and an- alytical models are likely more applicable to different water bodies than the empirical or semiempirical methods (Binding et al., 2012, 2010; Chen et al., 2015b; Giardino et al., 2007; Ma et al., 2010; Sipelgas et al., 2009). However, there are still limitations of the application due to the difficulties of retrieval or inaccuracies on initialization parameters (Binding et al., 2012; Chen et al., 2015b; Ma et al., 2010; Wu et al., 2013). Therefore, the empirical (especially semiempirical) methods are still used to estimate TSS concentration and will continue to be used for a long time due to their simplicity and sufficient accuracies. It should be noted that the applications of empirical or semiempirical TSS models need to be revalidated in different regions and periods because they are largely region-, time- or environment-dependent (Wu et al., 2013). We found that previous empirical or semiempirical Landsat-based TSS retrieval models vary greatly in their main forms of a single band or multiple bands for different estuaries and coasts (Ma et al., 2010; Wu et al., 2013).

The TSS models of a single band include linear function (Fraser, 1998; Islam et al., 2001; Nas et al., 2010; Rao et al., 2009), exponential or logarithmic function (Keiner and Yan, 1998; Wu et al., 2013; Zhang et al., 2014), and quadratic function (Chen et al., 2014). Those models have been easily applied to many regions because they not only have the simple forms but also more choice of remote sensing data. We know that the sensitivity of satellite sensor bands is different for different TSS concentrations. Many studies have proven that reflectance in the red band increases with increasing TSS concentrations, but tends towards convergence or keeps stable due to saturation effect under high TSS concentrations (Ritchie and Zimba, 2006; Feng et al., 2014), while the reflectance in the near-infrared band is more sensitive to high TSS concentrations compared to low TSS concentrations (Chen et al., 2015b; Feng et al., 2014; Hu et al., 2004; Wang et al., 2010). Thus, those models of a single band have limited applications in regions with a wide dynamic range of TSS concentration.

Models that combined multiple bands worked better than those with a single band in avoiding the effect of saturation for water bodies of high TSS concentrations and have been applied widely (Dekkera et al., 2001; Doxaran et al., 2003; Feng et al., 2014; Montanher et al., 2014; Oyama et al., 2009; Wang et al., 2016). Although the band combination includes band ratio (Doxaran et al., 2003; Lathrop et al., 1991; Ritchie and Cooper, 1991; Topliss et al., 1990; Wang et al., 2016) and other complex forms (Dekkera et al., 2001; Li et al., 2010; Oyama et al., 2009; Song et al., 2011; Zhang et al., 2015), these models of multiple-band combination can be also classified into linear, exponential, logarithmic or quadratic function. Besides quadratic forms of models (Chen et al., 2014; Ritchie and Cooper, 1991; Topliss et al., 1990), most of those empirical or semiempirical TSS retrieval models are simple monotonic functions. Monotonic function has some potential issues. One is that the change of band reflectance corresponds to the fixed change of TSS concentrations, which may be un- 
realistic, such as linear function. Another is that a very small change of band reflectance can cause exaggerated estimation of TSS concentrations, such as exponential and logarithmic function. Although some non-monotonic functions could avoid the potential issues, it is widely believed that there is no existing regional or universal empirical or semiempirical TSS retrieval model for all water bodies (Ma et al., 2009; Tang et al., 2005; Wu et al., 2013).

Recently, we published a short conference paper (Wang et al., 2016), which stated that the quadratic TSS model could be a new method for estimating the wide-range TSS concentrations of multiple estuaries and coasts. However, the model lacks necessary analysis and discussion of results due to limitation of space. Besides, our previous model (Wang et al., 2016) could not be applied to remote sensing data for the reason that each value of reflectance does not correspond to a unique TSS concentration.

Based on the above analysis, this study intends to develop a Landsat-based model with better adaptability and robustness for retrieving TSS concentrations in estuaries and coasts. To achieve this goal, the applicability of more than 20 previous Landsat-based models was reviewed and further analyzed. We focus on the models using a multiple-band combination, and the form of models belongs to non-monotonic function. This paper was organized as follows. In situ data, pre-processing and Landsat imagery are described along with the atmospheric correction method and assessment method of simulation model accuracy in Sect. 2. The TSS retrieval model, validation and the spatial analysis of TSS concentration mapped from Landsat imagery and EO-1 Hyperion imagery are presented in Sect. 3. Finally, the summary and conclusions are given in Sect. 4.

\section{Materials and methods}

\subsection{Study areas}

The study areas, including five regions of China, are listed as follows.

Region I, the Xuwen coast (Fig. 1b), located between latitudes $20.1-20.5^{\circ} \mathrm{N}$ and longitudes $109.8-110.1^{\circ} \mathrm{E}$, is the important Coral Reefs National Nature Reserve with the most plentiful coral species because of its less turbid waters. The good water quality is due to less water discharge $(8.6 \times$ $10^{8} \mathrm{~m}^{3}$ year $^{-1}$ on average $)$ and sediment load $\left(3 \times 10^{4} \mathrm{tyr}^{-1}\right.$ on average) and the protection of coral reefs (Wang et al., 2002). It was reported that the coral reefs are not growing as well as before (Zhao et al., 2011). Researchers believe that this is mainly caused by the increasing TSS concentration, declination of water transparency, and decreasing water temperature due to excessive fish farming, overfishing and industrial pollution (Chen et al., 2015b). The coastal land development is also an important reason.
Region II, the Moyangiiang River estuary (Fig. 1c), is located between latitudes $21.65-21.9^{\circ} \mathrm{N}$ and longitudes 112 $112.2^{\circ} \mathrm{E}$, southwest of Guangdong Province. The source of the Moyangjiang River is in Yangchun County, and it has a length of $199 \mathrm{~km}$ and a drainage area of more than $6 \times 10^{3} \mathrm{~km}^{2}$. The annual mean surface runoff of the Moyangjiang River is $8.21 \times 10^{9} \mathrm{~m}^{3}$ and sediment load is $3.27 \times 10^{5}$ tyr on average. The Moyangjiang River crosses Yangchun, Yangdong and Jiangcheng counties (districts) and flows into the South China Sea.

Region III, the Pearl River estuary (Fig. 1d), is located between latitudes $21.9-23^{\circ} \mathrm{N}$ and longitudes $113.15-114.1^{\circ} \mathrm{E}$. The Pearl River is the fourth longest $(2320 \mathrm{~km})$ in China with a drainage area of $4.53 \times 10^{5} \mathrm{~km}^{2}$, and its annual runoff $\left(3.26 \times 10^{11} \mathrm{~m}^{3}\right)$ is only smaller than the Yangtze River. The sediment load of the Pearl River is $7.53 \times 10^{7} \mathrm{tyr}^{-1}$ on average. The Pearl River crosses eight waterways (Humen, Jiaomen, Hongqimen, Hengmen, Modaomen, Jitimen, Hutiaomen and Yamen) located at six cities of Guangdong Province and pours into South China Sea. As we all know, the estuary of the Pearl River and the adjacent coast suffer severely from combined pollution (Ma and Wang, 2003) which mainly comes from industrial production, residential life and seawater intrusion (Chen et al., 2009a).

Region IV, the Hanjiang River estuary (Fig. 1e), is located between latitudes $23.2-23.6^{\circ} \mathrm{N}$ and longitudes 116.6$117^{\circ} \mathrm{E}$, east of Guangdong Province and southwest of Fujian Province. The Hanjiang River has a length of $470 \mathrm{~km}$ and has the second largest drainage area $\left(3.01 \times 10^{4} \mathrm{~km}^{2}\right)$ in Guangdong Province. The annual mean surface runoff of the Hanjiang River is $2.45 \times 10^{10} \mathrm{~m}^{3}$ with sediment load is $6.93 \times 10^{6} \mathrm{tyr}^{-1}$ on average. The lower reaches of the Hanjiang River include Beixi waterway located in the northeast, Dongxi waterway located in the middle and Xixi waterway located in the west. Xixi waterway also crosses with the three waterways of Waishahe, Xinjinhe and Meixi and flows into the South China Sea. Waishahe, Xinjinhe and Meixi waterways are located in east, middle and west of Longhu District, Shantou, in Guangdong Province, respectively.

Region V, the Yangtze River estuary (Fig. 1f), is located between latitudes $30.8-31.8^{\circ} \mathrm{N}$ and longitudes 121.55$122.4^{\circ} \mathrm{E}$. The Yangtze River is the largest river in China, and has a length of $6280 \mathrm{~km}$ and a drainage area of $1.8 \times 10^{6} \mathrm{~km}^{2}$. The annual mean surface runoff of the Yangtze River is $9.2 \times 10^{11} \mathrm{~m}^{3}$, with a sediment load of $4.8 \times 10^{8} \mathrm{tyr}^{-1}$ on average (Feng et al., 2014). Such huge terrestrial input not only loads to its extremely turbid waters but also impacts on the optical properties of this region. It is reported that the environment of the Yangtze River estuary is getting worse due to the rapid developments and urbanization in the surrounding industrial areas (Chen et al., 2015a; Hsu and Lin., 2010). As a result, there are more and more studies focusing on this region due to its important ecological and economic role (Chen et al., 2015a; Feng et al., 2014; Shen et al., 2010). 

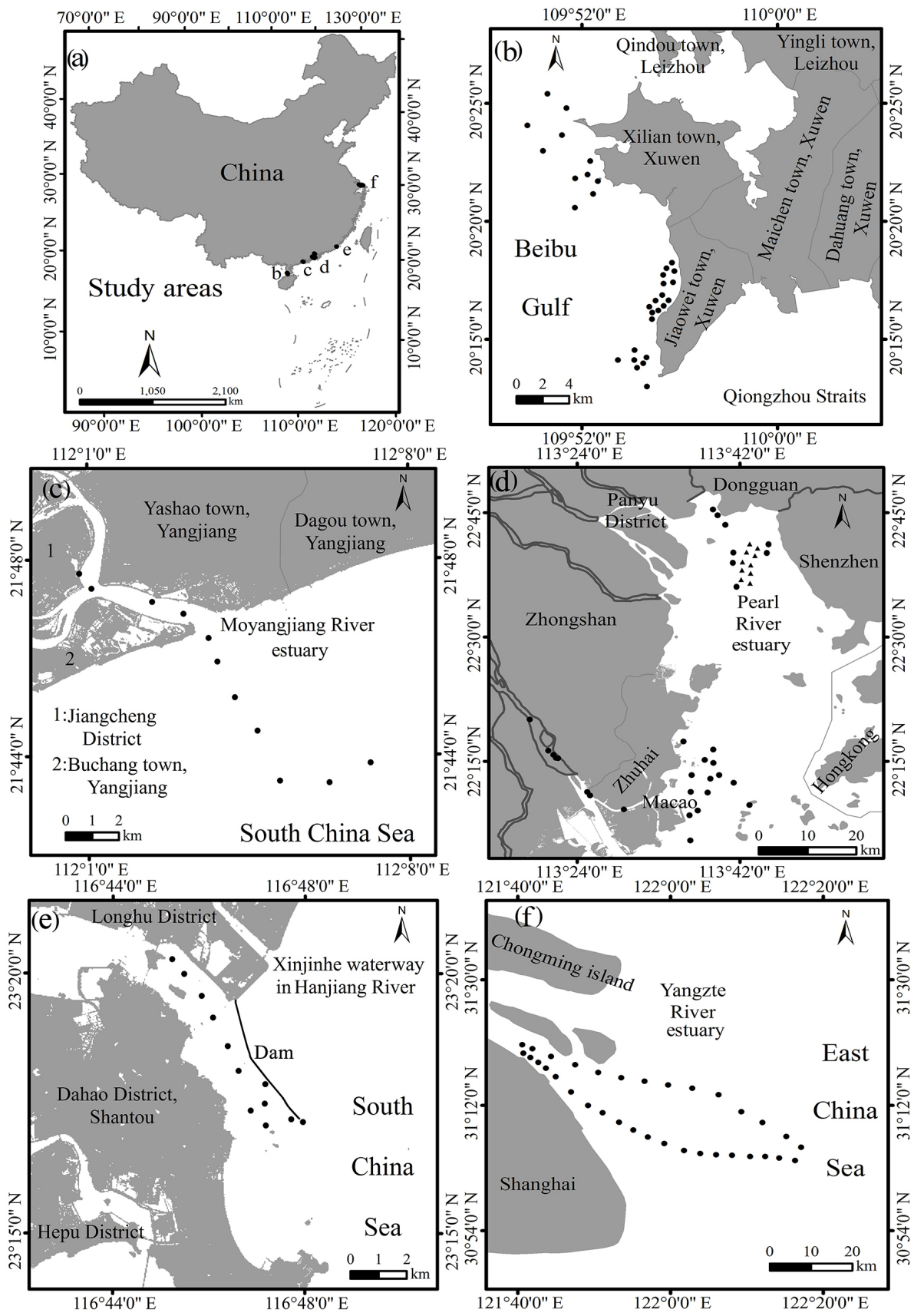

Figure 1. (a) Study areas and locations of in situ data (black dots and triangles). (b) Xuwen coast; (c) Moyangjiang River estuary; (d) Pearl River estuary; (e) Hanjiang River estuary; (f) Yangtze River estuary.

Water bodies of the study areas were extracted based on a method developed by Jiang et al. (2014). The difference in spectral profile across water and clouds was used to mask clouds (Chen et al., 2009b, 2011a). We find that the reflectance of water is usually less than 0.05 in the nearinfrared band while the reflectance of cloud is usually higher than 0.1 in the near-infrared band in the study areas. Thus, the clouds were masked based on reflectance that is higher than 0.05 in the near-infrared band.

\subsection{In situ and satellite data}

The 129 in situ samples were collected from the abovementioned five regions of China, and their positions were recorded by Trimble global positioning system (real time) with root mean square errors of $1-4 \mathrm{~m}$ (shown in Fig. 1). Samples for the study were taken from a river downstream towards the sea (including shoals, channels, maximum turbidity zones), mainly based on the wide TSS changes of each 
Table 1. Information about the study areas and in situ data.

\begin{tabular}{|c|c|c|c|c|c|}
\hline Location & $\begin{array}{l}\text { Hydrologic features } \\
\text { (length, drainage area, } \\
\text { mean surface runoff and } \\
\text { sediment discharge) }\end{array}$ & Date & Samples & Measurements & $\begin{array}{l}\text { Number of } \\
\text { synchronous } \\
\text { samples with } \\
\text { satellite }\end{array}$ \\
\hline Region I & $\begin{array}{l}8.6 \times 10^{8} \mathrm{~m}^{3} \mathrm{yr}^{-1} \\
3 \times 10^{4} \mathrm{tyr}^{-1}\end{array}$ & $\begin{array}{l}3 \text { Dec } 2010 \\
\text { 13-14 Jan } 2013\end{array}$ & $\begin{array}{l}10 \\
22\end{array}$ & $\begin{array}{l}\text { Reflectance, TSS } \\
\text { Reflectance, TSS }\end{array}$ & $\begin{array}{l}\text { No } \\
\text { No }\end{array}$ \\
\hline Region II & $\begin{array}{l}199 \mathrm{~km}, 6 \times 10^{3} \mathrm{~km}^{2} \\
8.21 \times 10^{9} \mathrm{~m}^{3} \mathrm{yr}^{-1} \\
3.27 \times 10^{5} \mathrm{tyr}^{-1}\end{array}$ & 6 Dec 2013 & 11 & Reflectance, TSS & 7, OLI \\
\hline Region III & $\begin{array}{l}2320 \mathrm{~km}, 4.53 \times 10^{5} \mathrm{~km}^{2} \\
3.26 \times 10^{11} \mathrm{~m}^{3} \mathrm{yr}^{-1} \\
7.53 \times 10^{7} \mathrm{tyr}^{-1}\end{array}$ & $\begin{array}{l}27 \text { Dec } 2007 \\
2 \text { Nov } 2012\end{array}$ & $\begin{array}{l}5 \\
18\end{array}$ & $\begin{array}{l}\text { Reflectance, TSS } \\
8 \text { samples with } \\
\text { Reflectance and } \\
\text { TSS; } 10 \text { samples } \\
\text { with TSS only } \\
\text { Reflectance, TSS } \\
\text { Reflectance, TSS }\end{array}$ & $\begin{array}{l}\text { No } \\
13 \text {, Hyperion }\end{array}$ \\
\hline Region IV & $\begin{array}{l}470 \mathrm{~km}, 3.01 \times 10^{4} \mathrm{~km}^{2} \\
2.45 \times 10^{10} \mathrm{~m}^{3} \mathrm{yr}^{-1} \\
6.93 \times 10^{6} \mathrm{tyr}^{-1}\end{array}$ & 1 Dec 2013 & 12 & Reflectance, TSS & 9, OLI \\
\hline Region V & $\begin{array}{l}6280 \mathrm{~km}, 1.8 \times 10^{6} \mathrm{~km}^{2} \\
9.2 \times 10^{11} \mathrm{~m}^{3} \mathrm{yr}^{-1} \\
4.8 \times 10^{8} \mathrm{tyr}^{-1}\end{array}$ & $14-15$ Oct 2009 & 34 & Reflectance, TSS & No \\
\hline
\end{tabular}

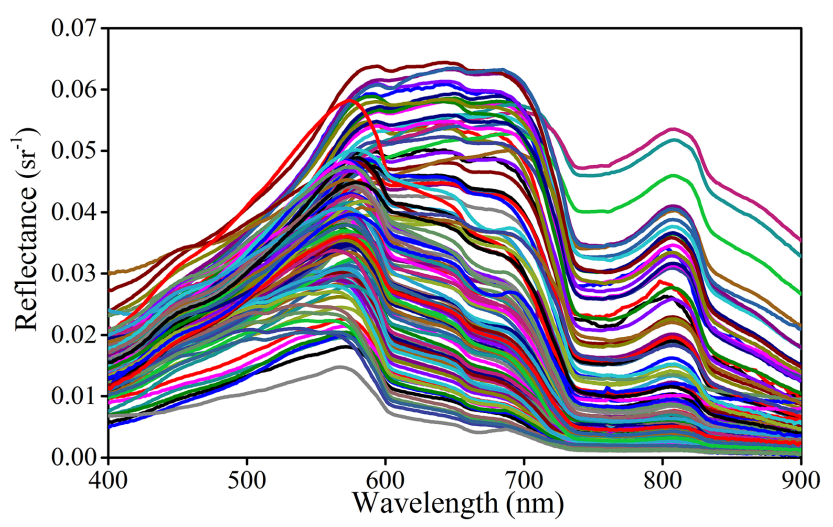

Figure 2. A total of 119 spectra were collected from study areas by ASD.

estuary and coastal area for representing the wide variability of TSS concentrations (Fig. 1b-f, dots and triangles). Among the 129 samples, 32 samples were collected from the Xuwen coast on 3 December 2010 and 13 to 14 February 2013; 11 samples were collected from the Moyangjiang River estuary on 6 December 2013; 40 samples were collected from the Pearl River estuary on 19 to 21 December 2006, 27 December 2007 and 2 November 2012; 12 samples were collected from the Hanjiang River estuary on 1 December 2013; and
34 samples were collected from the Yangtze River estuary on 14 to 15 October 2009. The ASD field spectral measurements and synchronous water samples of the abovementioned 119 samples were carried out from 10:00 to 15:00 LT (Fig. 1b-f, dots, Table 1). Besides, another 10 samples with TSS concentrations from the Pearl River estuary on 21 December 2006 were collected synchronously with EO-1 Hyperion imagery only (Fig. 1d, triangles, Table 1). The spectra were measured based on above-water spectrum measurement method that could effectively avoid the influence of sun and sky glint, water vapor, aerosols, and vessel shadow (Tang et al., 2004a), which was widely applied to the water bodies such as estuaries and coasts of China (Chen et al., 2015a; Feng et al., 2014; Zhang et al., 2014). It should be noted that the distance from some samples (Fig. 1d) taken from Modaomen waterway of the Pearl River to the surrounding land is usually more than $200 \mathrm{~m}$. Thus, there is a small effect from the surrounding land on the reflectance of water body. Finally, the reflectance of water surface (Fig. 2) was calculated in the same way as Zhang et al. (2014) and Chen et al. (2015b). Water samples (about $1.5 \mathrm{~L}$ ) were collected within the water depth of $1 \mathrm{~m}$, and TSS concentrations were measured by a weighing method (Binding et al., 2012; Caballero et al., 2014).

TM, ETM+ and OLI sensors onboard the Landsat 5, 7 and 8 satellites (USGS program, 1982), respectively, have a spa- 

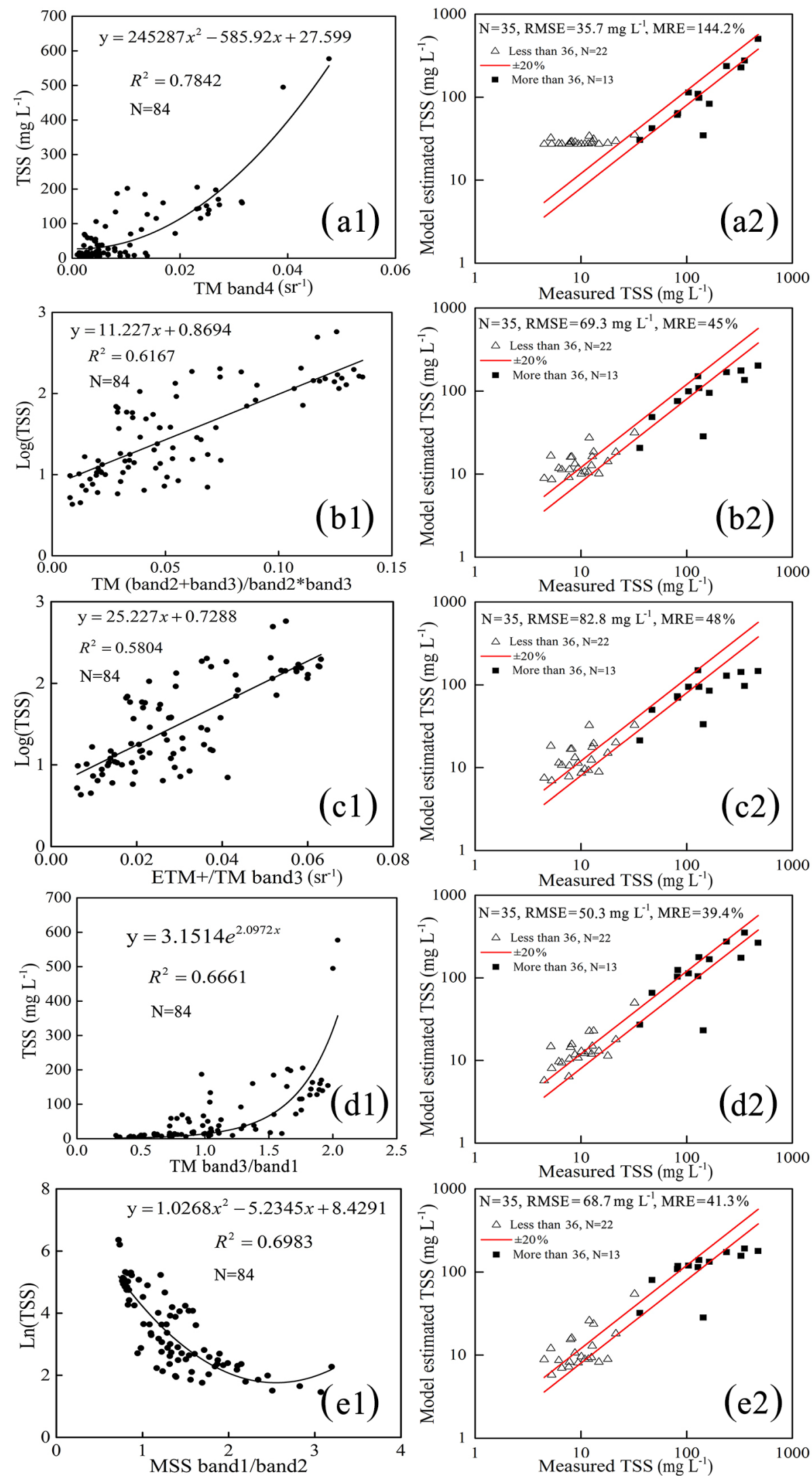

Figure 3. The recalibration and validation of previous five TSS retrieval models based on 119 in situ samples. The models were developed by (a) Chen et al. (2014), (b) Li et al. (2010), (c) Zhang et al. (2014), (d) Lathrop et al. (1991), (e) Ritchie and Cooper (1991), respectively. 

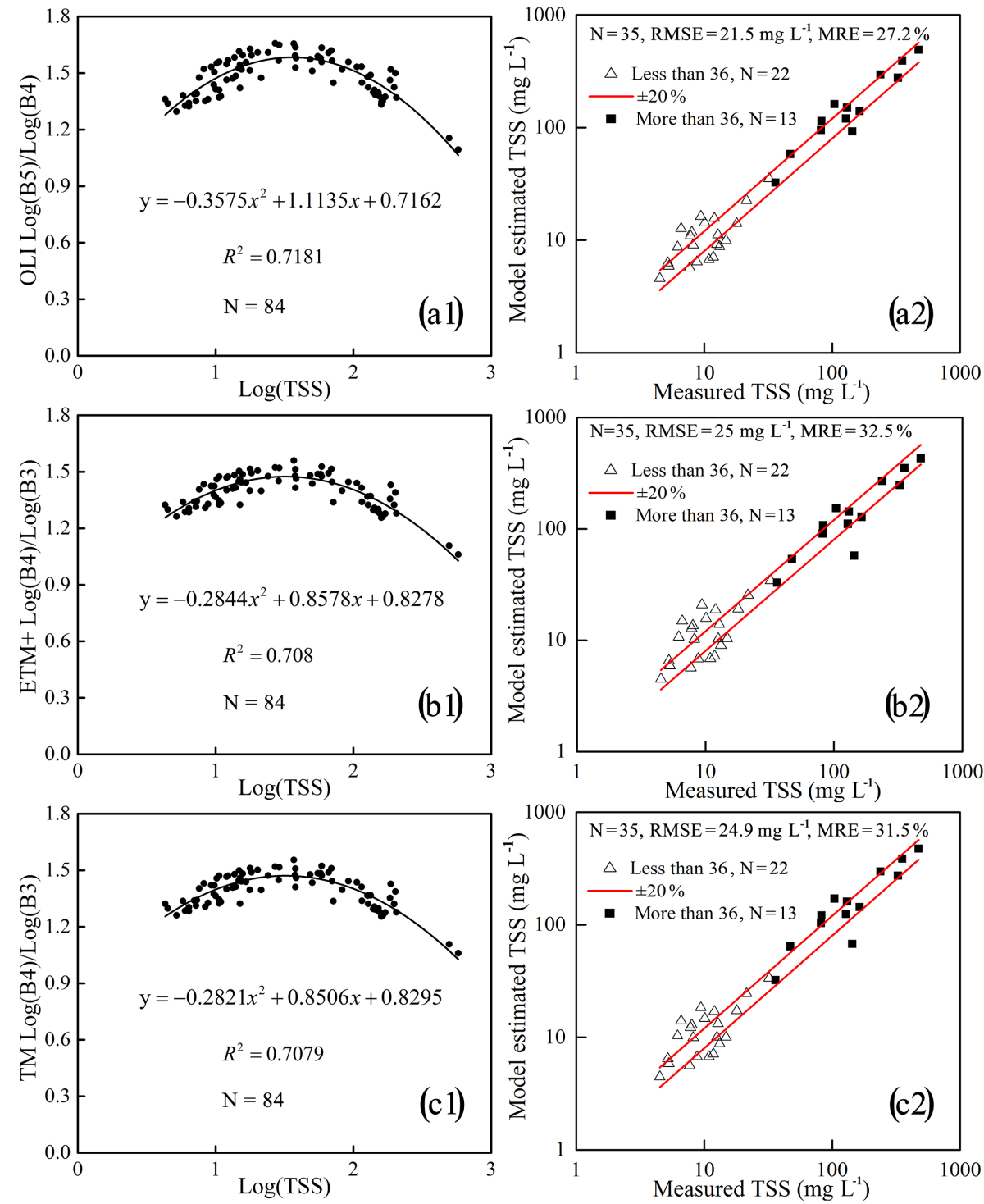

Figure 4. The calibration and validation results of TSS retrieval models: based on 119 in situ data for (a) OLI, (b) ETM+ and (c) TM.
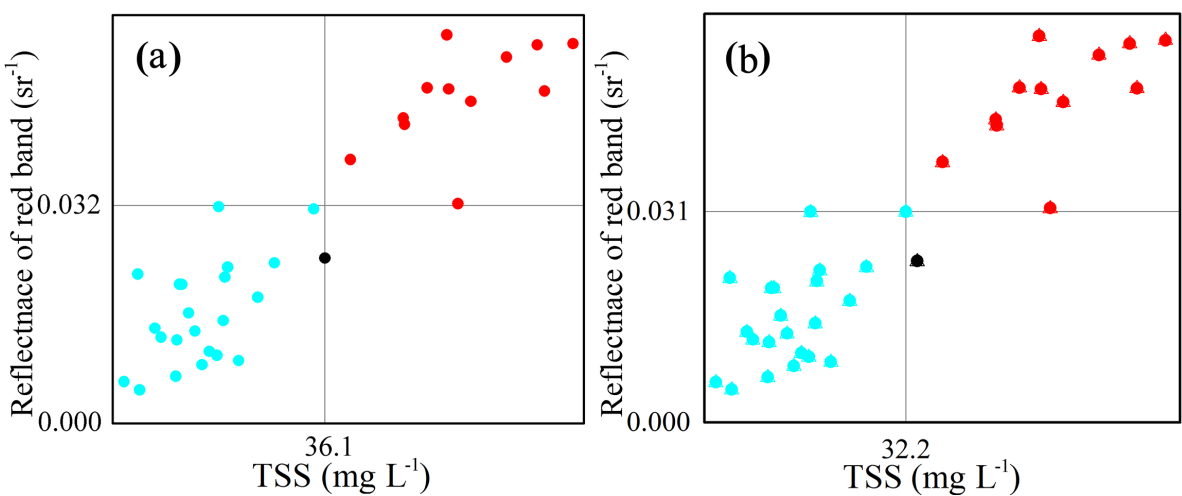

Figure 5. Relationship between the Landsat red-band reflectance and corresponding TSS concentration. (a) OLI sensor; (b) ETM+ and TM sensors. 

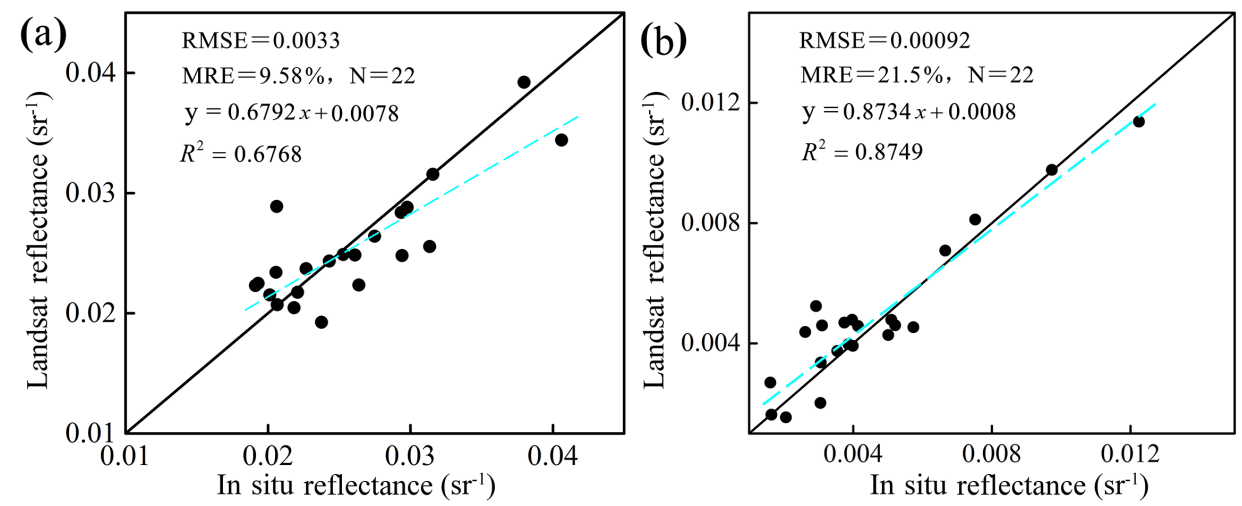

Figure 6. Scatter plot of Landsat measured reflectance vs. in situ reflectance. The former is calculated by averaging over a box of $3 \times 3$ pixel centered samples. (a) Red band; (b) near-infrared band.

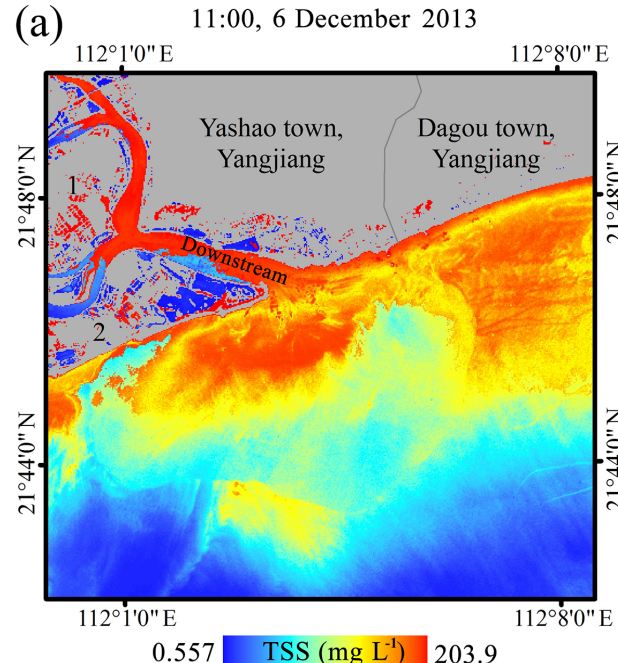

(c)

10:41, 1 December 2013

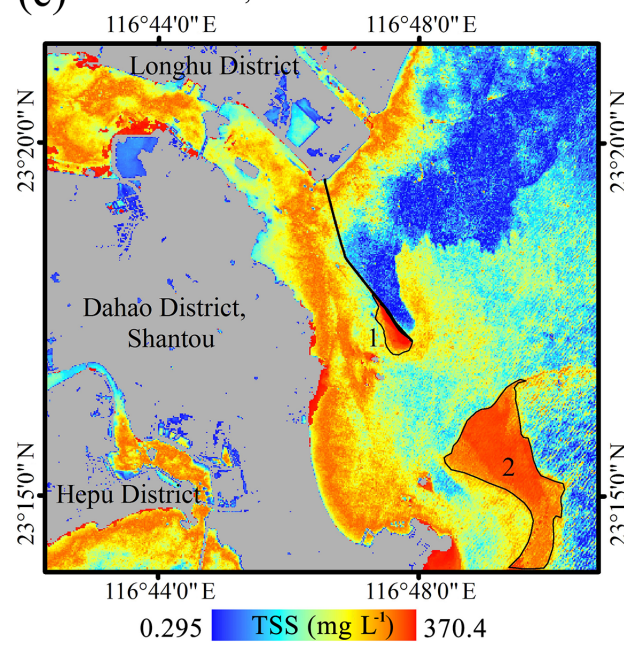

(b) $\quad 10: 48,2$ November 2012

(d)
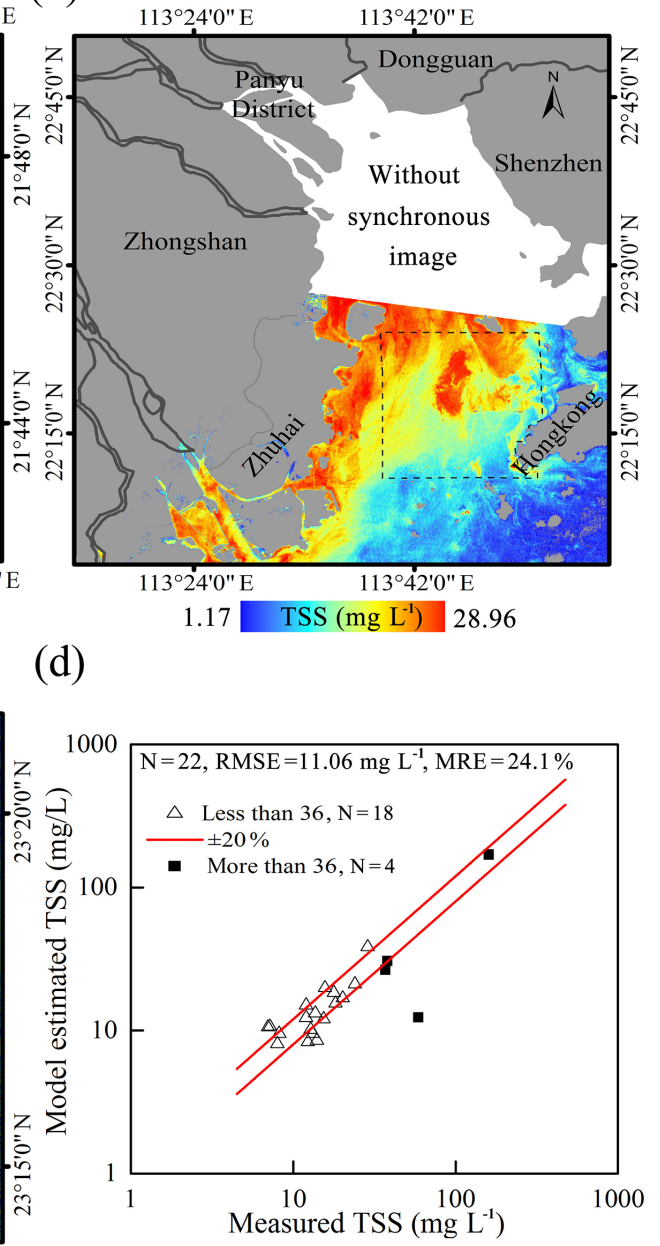

Figure 7. Estimated TSS concentrations based on the QRLTSS model in Moyangjiang River estuary at 11:00 (LT, OLI) on 6 December 2013 (a), Pearl River estuary at 10:48 (LT, ETM+) on 2 November 2012 (b), Hanjiang River estuary at 10:41 (LT, OLI) on 1 December 2013 (c), and comparison between the in situ measured and Landsat imagery inversed TSS concentrations of three estuaries (d). Color scale is the legend of the TSS concentrations, in milligrams per liter $\left(\mathrm{mg} \mathrm{L}^{-1}\right)$. 


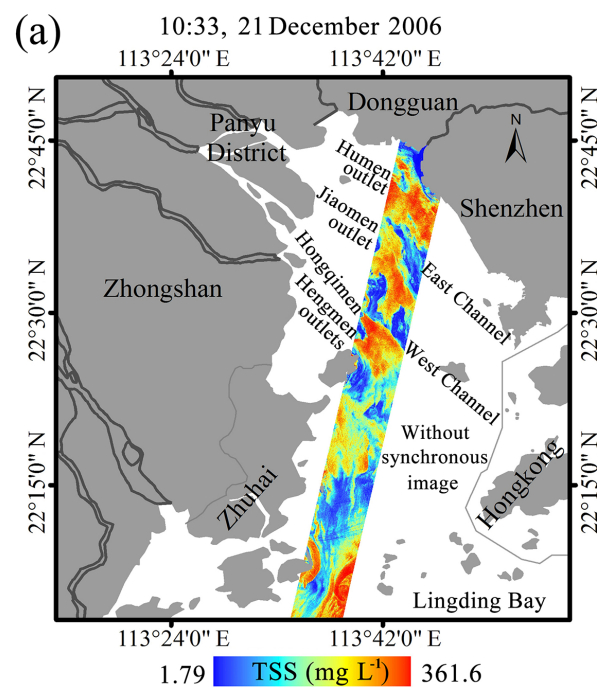

(b)

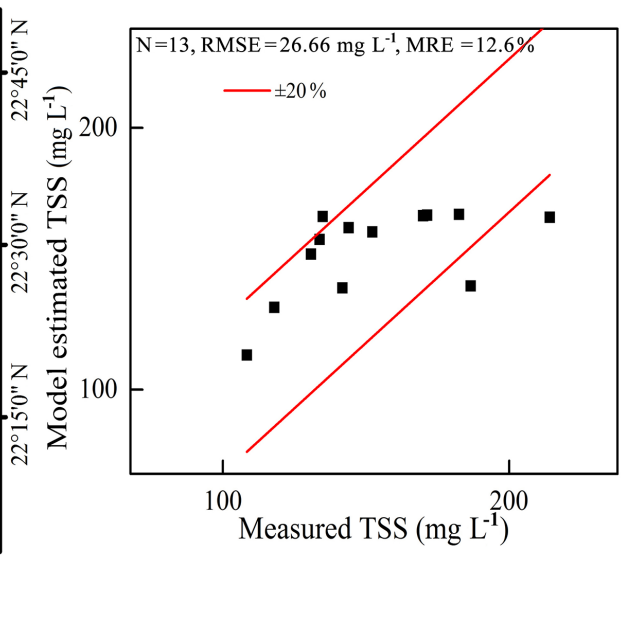

Figure 8. Estimated TSS concentrations based on the QRLTSS model from EO-1 Hyperion imagery in Pearl River estuary at 10:33 (LT), on 21st December 2006 (a) and comparison between the in situ measured and EO-1 Hyperion imagery inversed TSS concentrations (b). Color scale is the legend of the TSS concentrations, in milligrams per liter $\left(\mathrm{mg} \mathrm{L}^{-1}\right)$.

tial resolution of about $30 \mathrm{~m}$, with more than seven bands spanning from a visible to infrared wavelength. The spectral bands of the OLI sensor, while similar to TM and ETM+ sensor, provide enhancement of prior Landsat instruments, with the addition of two new spectral bands: a deep blue visible channel (band 1) specifically designed for water resources and coastal zone investigation, and a new infrared channel (band 9) for the detection of cirrus clouds. A new quality-assurance band is also included with each data product. This provides information on the presence of features such as clouds, water, and snow (https://landsat.usgs.gov/, USGS, 1982). The data quality (signal-to-noise ratio) and radiometric quantization (12 bit) of the OLI and TIRS is higher than previous Landsat instruments ( 8 bit for TM and ETM+), providing significant improvement in the ability to detect changes on the Earth's surface. The principal functional differences between the ETM+ and the former TM series are the addition of a $15 \mathrm{~m}$ resolution panchromatic band and two 8 bit "gain" ranges. The ETM+ images are acquired in either a low- or high-gain state. The goal of using two gain settings is to maximize the sensors' 8 bit radiometric resolution without saturating the detectors, while the L4 and L5 TM radiometric calibration uncertainty of the at-sensor spectral radiances due to change of gains was around $5 \%$ and was somewhat worse (Chander et al., 2009). However, after the revision of gains, Landsat imagery can basically be fit for quantifying the optical properties in oceans, lakes, estuaries and coasts which have been explored in many studies, although they were originally designed for observation of land targets (Montanher et al., 2014; Nas et al., 2010; Volpe et al., 2011; Wu et al., 2013; Zhang et al., 2014).
Due to frequent cloud coverage in estuaries and coasts, as well as the low temporal resolution (16d) of the Landsat satellite (Bailey and Werdell., 2006), this study obtained three Landsat images with good quality that can only be matched with synchronous in situ measurements of three study regions (Table 1). The first image from ETM+ (path/row $=122 / 45$ ) was captured on 2 November 2012, covering part of the Pearl River estuary (Fig. 1d). The second image (path/row $=120 / 44$ ) from OLI was captured on 1 December 2013, covering the Hanjiang River estuary (Fig. 1e). The third image (path/row $=123 / 45$ ) from OLI was captured on 6 December 2013, covering the Moyangjiang River estuary (Fig. 1c). It should be noted that the scan line corrector (SLC) of Landsat 7 ETM+ has failed since 31 May 2003. However, there are still many research works using the SLCfree data that are repaired using local self-adaptive regression analysis (Zhang et al., 2014). The repaired data in our study are provided by the International Scientific Data Service Platform, Computer Network Information Center, Chinese Academy of Sciences (http://www.gscloud.cn/).

In addition, an EO-1 Hyperion (NASA, 2001) image (path/row $=122 / 44$ ) was captured on 21 December 2006, covering part of the Pearl River estuary (Fig. 1d). With spectral coverage ranging from 400 to 2500 and $10 \mathrm{~nm}$ (sampling interval) of contiguous bands of the solar reflected spectrum, Hyperion's spatial resolution is $30 \mathrm{~m}$ with a $7.7 \mathrm{~km}$ imagery swath and $185 \mathrm{~km}$ length (http://eo1.usgs.gov). Hyperion is also well suited for retrieving spatial distributions of watercolor constituents in the Pearl River estuary (Chen et al., 2009a). The Hyperion data were used for further validation of TSS retrieval model here. 


\subsection{Atmospheric correction method}

There are many signals at visible wavelengths from atmospheric path radiance, which prevents the proper interpretation of original image (Chen et al., 2009b), especially for a water body of low reflectance. Thus, the atmospheric correction is a necessary step before the remote sensing inversion (Gordon and Wang., 1994; Zhang et al., 2014). The commonly used methods of atmospheric correction include the simple dark object subtraction (DOS), fast line-of-sight atmospheric analysis of spectral hypercubes (FLAASH), and second simulation of satellite signal in the solar spectrum (6S) models. In addition, the regression analysis of spectral bands is also a common method used for atmospheric correction (Chen et al., 2011a; Hedley et al., 2005; Hochberg et al., 2003; Mei et al., 2001; Montanher et al., 2014). All in all, each atmospheric correction method has its advantages and disadvantages.

The $6 \mathrm{~S}$ code the study used is the improved version of simulation of the satellite signal in the solar spectrum $(5 \mathrm{~S})$, developed by the Laboratoire d'Optique Atmospherique (Vermote et al., 1997). The $6 \mathrm{~S}$ atmospheric correction model can also correct the skylight reflection (sun and sky glint) following the Snell-Fresnel laws, environmental effects and directional target effects (Doxarana et al., 2002), and the Fresnel reflection is partially reduced by the presence of land in estuarial and coastal waters (Vidot and Santer, 2005). The $6 \mathrm{~S}$ code is frequently used for atmospheric correction of Landsat imagery based on the Landsat Ecosystem Disturbance Adaptive Processing System (LEDAPS, a Landsat atmospheric correction code base funded by NASA's Terrestrial Ecology Program) (Feng et al., 2013; Ju et al., 2012; Maiersperger et al., 2013; Masek et al., 2006; USGS project, 2004). Compared to the MODIS daily surface reflectance and normalized bidirectional distribution function-adjusted reflectance measurements, the global surface reflectance dataset from Landsat created by LEDAPS has a high accuracy (root mean squared deviation: 1.3-3.5\%) (Feng et al., 2013; Maiersperger et al., 2013). Thus, the LEDAPS software was chosen for atmospheric correction in this study. We assumed the continental aerosol type because the northeast monsoon was blowing from the land in the study. The aerosol optical thickness was derived independently from each Landsat acquisition using the dark dense vegetation (DDV) approach (Kaufman and Tanré, 1996). Critical atmospheric parameters of the $6 \mathrm{~S}$ model, including water vapor at a resolution of 2.5 by $2.5^{\circ}$ (http://dss.ucar.edu/datasets/ds090.0/) and ozone concentrations at a resolution of $1^{\circ}$ latitude and $1.25^{\circ}$ longitude, were collected from National Centers for Environmental Prediction (NCEP) and Total Ozone Mapping Spectrometer (TOMS) and NOAA's Television Infrared Observation Satellite Program (TIROS) Operational Vertical Sounder (TOVS), respectively (Feng et al., 2013; Ju et al., 2012; Masek et al., 2006). Rayleigh scattering was adjusted to local conditions by a static $0.05^{\circ}$ digital topography dataset (de- rived from the $1 \mathrm{~km}$ GTopo30) and NCEP surface pressure data (Feng et al., 2013; Masek et al., 2006). All the parameters are automatically called corresponding to each Landsat image when LEDAPS runs.

\subsection{Band response function application of Landsat for field spectra}

Before establishing a TSS retrieval model, the water surface reflectance measured in the field was convoluted with the Landsat band response functions to derive the band-weighted reflectance data using Eq. (1). It is also a critical step for the application of TSS retrieval model from ground spectral data to remote sensing imagery.

$$
R(\text { band })=\frac{\sum_{\text {band }_{\text {min }}}^{\text {band }_{\text {max }}} f\left(\lambda_{\text {band }}\right) r\left(\lambda_{\text {band }}\right)}{\sum_{\text {band }_{\text {min }}}^{\text {band }_{\max }} f\left(\lambda_{\text {band }}\right)},
$$

where band $_{\min }$ and band $\mathrm{max}_{\max }$ are the lower and upper limits of the Landsat band in red and near-infrared bands, respectively; $r(\lambda)$ is the water surface reflectance, and $f(\lambda)$ is the spectral response function of Landsat sensors (http: //Landsat.usgs.gov). The simulated " $R$ (band)", corresponding to all bands of Landsat OLI, ETM+ and TM, was calculated for each spectrum.

\subsection{Accuracy assessment method of models}

In order to validate the accuracy of the TSS spectral models, atmospheric correction and mapping of TSS concentrations, the most frequently used methods (Chen et al., 2009b; Feng et al., 2014; Zhang et al., 2014), including the determination coefficient $\left(R^{2}\right)$, the RMSE and mean relative error (MRE), were also used in the study for convenience of comparison by different readers.

$$
\begin{aligned}
\mathrm{RMSE} & =\sqrt{\frac{\sum_{i=1}^{i=n}\left(x_{i}-x_{i}^{\prime}\right)^{2}}{n},} \\
\mathrm{MRE} & =\frac{\sum_{i=1}^{i=n}\left|\frac{x_{i}-x_{i}^{\prime}}{x_{i}}\right|}{n} \times 100 \%,
\end{aligned}
$$

where $x_{i}$ is the observed value, $x_{i}^{\prime}$ is the modeled value, $i$ is the $i$ th element, and $n$ is the number of elements.

\section{Results and discussions}

\subsection{Evaluation of previous Landsat-based TSS models}

The previous Landsat-based TSS retrieval models (Table 2) were calibrated and validated again with the optimization of 
Table 2. Review of previous TSS or turbidity retrieval models using Landsat imagery.

\begin{tabular}{|c|c|c|c|}
\hline Data & Model & Study area & Reference \\
\hline TM Bands 2, 4 & $\mathrm{TSS}=29.022 \cdot \exp (0.0335 \cdot(\mathrm{B} 4 / \mathrm{B} 2))$ & $\begin{array}{l}\text { Gironde and Loire } \\
\text { Estuaries }\end{array}$ & Doxaran et al. (2003) \\
\hline MSS Bands 5, 6 & $\ln (\mathrm{TSS})=1.4 \cdot(\mathrm{B} 5 / \mathrm{B} 6)^{2}-6.2 \cdot(\mathrm{B} 5 / \mathrm{B} 6)+10.8$ & $\begin{array}{l}\text { The Bay of Fundy and } \\
\text { the Beaufort Sea }\end{array}$ & Topliss et al. (1990) \\
\hline TM Bands 1, 3, 4 & Turbidity $=11.31 \cdot(\mathrm{B} 4 / \mathrm{B} 1)-2.03 \cdot \mathrm{B} 3-16.42$ & Chagan Lake & Song et al. (2011) \\
\hline TM Band 4 & Turbidity $=16.1 \cdot \mathrm{B} 4-12.7$ & $\begin{array}{l}\text { Nebraska Sand Hills } \\
\text { Lakes }\end{array}$ & Fraser (1998) \\
\hline TM Band 3 & Turbidity $=10 \cdot \mathrm{B} 3-24.8$ & & \\
\hline TM Band 1 & Turbidity $=19 \cdot \mathrm{B} 1-97.9$ & & \\
\hline TM Band 2 & Turbidity $=6.4 \cdot \mathrm{B} 2-28$ & & \\
\hline TM Band 3 & $\mathrm{TSS}=69.39 \cdot \mathrm{B} 3-201$ & $\begin{array}{l}\text { Ganges and Brahmapu- } \\
\text { tra rivers }\end{array}$ & Islam et al. (2001) \\
\hline MSS Bands 1, 2 & $\ln (\mathrm{TSS})=2.71 \cdot(\mathrm{B} 1 / \mathrm{B} 2)^{2}-9.21 \cdot(\mathrm{B} 1 / \mathrm{B} 2)+8.45$ & $\begin{array}{l}\text { Enid Reservoir in } \\
\text { north-central Missis- } \\
\text { sippi }\end{array}$ & Ritchie and Cooper (1991) \\
\hline TM Band 3 & $\log (\mathrm{TSS})=0.098 \cdot \mathrm{B} 3+0.334$ & Delaware Bay & Keiner and Yan (1998) \\
\hline TM Bands 2, 3 & $\mathrm{TSS}=0.7581 \cdot \exp (61.683 \cdot(\mathrm{B} 2+\mathrm{B} 3) / 2)$ & Southern Frisian lakes & Dekkera et al. (2001) \\
\hline TM Bands 1,3 & $\mathrm{TSS}=0.0167 \cdot \exp (12.3 \cdot \mathrm{B} 3 / \mathrm{B} 1)$ & $\begin{array}{l}\text { An embayment of Lake } \\
\text { Michigan }\end{array}$ & Lathrop et al. (1991) \\
\hline TM/ETM+ Band 3 & $\log (\mathrm{TSS})=44.072 \cdot \mathrm{B} 3+0.1591$ & Yellow River estuary & Zhang et al. (2014) \\
\hline \multirow[t]{2}{*}{ TM Band 3} & $\mathrm{TSS}=2.19 \cdot \exp (21.965 \cdot \mathrm{B} 3)$ & \multirow[t]{4}{*}{ Poyang Lake } & \multirow[t]{4}{*}{ Wu et al. (2013) } \\
\hline & $\begin{array}{l}\mathrm{TSS}=-9275.78 \cdot(\mathrm{B} 3)^{3}+8623.19 \cdot(\mathrm{B} 3)^{2} \\
-810.04 \cdot \mathrm{B} 3+23.44\end{array}$ & & \\
\hline \multirow[t]{2}{*}{ TM Bands 3, 4} & $\begin{array}{l}\mathrm{TSS}=5829.8 \cdot(\mathrm{B} 3-\mathrm{B} 4)^{3}+4165.09 \cdot(\mathrm{B} 3-\mathrm{B} 4)^{2} \\
-189.88 \cdot(\mathrm{B} 3-\mathrm{B} 4)+5.43\end{array}$ & & \\
\hline & $\mathrm{TSS}=3.411 \cdot \exp (21.998 \cdot(\mathrm{B} 3-\mathrm{B} 4))$ & & \\
\hline OLI Bands 2, 3, 8 & $\mathrm{TSS}=-191.02 \cdot \mathrm{B} 2+36.8 \cdot \mathrm{B} 3+172.66 \cdot \mathrm{B} 8+4.57$ & Xin'anjiang Reservoir & Zhang et al. (2015) \\
\hline TM Band 2 & $\mathrm{~B} 2=0.0044 \cdot \mathrm{TSS}+2.5226$ & Bhopal Upper Lake & Rao et al. (2009) \\
\hline TM Band 2, 3 & $\log (\mathrm{TSS})=6.2244 \cdot(\mathrm{B} 2+\mathrm{B} 3) / \mathrm{B} 2 \cdot \mathrm{B} 3+0.892$ & Yangtze estuary & Li et al. (2010) \\
\hline TM Band 3 & $\mathrm{TSS}=0.543 \cdot \mathrm{B} 3-7.102$ & Beysehir Lake & Nas et al. (2010) \\
\hline TM Band 4 & $\mathrm{TSS}=229457.695 \cdot(\mathrm{B} 4)^{2}+146.462 \cdot \mathrm{B} 4+5.701$ & Bohai gulf & Chen et al. (2014) \\
\hline
\end{tabular}

parameters based on the 119 in situ samples (84 in situ samples for calibration, the other 35 for validation). There were five comparatively better results of the simulation presented in Fig. 3 only due to the limitation of page space. The results indicated that the previous Landsat-based TSS models did not explain the TSS variation so well. The determination coefficient of calibration models in the five better TSS models (Fig. 3) was between 0.58 and 0.784 , corresponding to linear (Fig. 3c1) and quadratic (Fig. 3a1) models of single bands, respectively.
The five TSS retrieval models were further validated based on another 35 in situ samples within the range of 4.5$474 \mathrm{mg} \mathrm{L}^{-1}$. The results showed that minimum MRE was $39.4 \%$ from an exponential single-band model (Fig. 3d2), but its RMSE was $50.26 \mathrm{mg} \mathrm{L}^{-1}$. The quadratic single-band model (Fig. 3a2) got minimum RMSE (35.73 $\mathrm{mg} \mathrm{L}^{-1}$ ) but with a high MRE value of $144.2 \%$. Obviously, the quadratic single-band model is difficult to adapt for this study. However, for the exponential single-band model, the high RMSE prevented this form of model from applying as well, espe- 
cially when we took the TSS concentration of 22 validation data (lower than $36 \mathrm{mg} \mathrm{L}^{-1}$, Fig. 3 in triangles) into account. The RMSEs and MREs of the other three forms of models were $69.3 \mathrm{mgL}^{-1}$ and $45 \%, 82.7 \mathrm{mgL}^{-1}$ and $48 \%$ for the linear model (Fig. 3b2 and c2), $68.7 \mathrm{mg} \mathrm{L}^{-1}$ and $41.3 \%$ for the quadratic model (Fig. 3e2), respectively. In contrast, the non-monotonic function, quadratic model of the ratio of bands (Fig. 3e) had a better performance among the five examined TSS models. But, we still expect that there would be a TSS model with high calibration and validation accuracy simultaneously for estuaries and coasts of China by Landsat imagery.

\subsection{Development of QRLTSS model}

In order to develop a Landsat-based model with higher calibration and validation accuracy, some MODIS-based TSS retrieval models (Chen et al., 2009b, 2011a, b, 2015b; Wang et al., 2010) were referred to. These models made full use of the relationship between the ratio of logarithmic transformation of the red band and near-infrared band and logarithmic transformation of TSS concentration. Thus, following the feature of these MODIS-based models, we improved the model (Fig. 3e1) developed by Ritchie and Cooper (1991), under the MATLAB environment, shown in Fig. 4.

From Figs. 3 and 4a1, b1 and c1, we found that the quadratic model of the ratio of logarithmic transformation of red band and near-infrared band and logarithmic transformation of TSS concentration (QRLTSS, Eq. 4) has a higher calibration accuracy than most of the previous TSS models, no matter whether it is Landsat OLI, ETM+ or TM sensor.

$\frac{\log \left(R_{1}\right)}{\log \left(R_{2}\right)}=a \cdot(\log (\mathrm{TSS}))^{2}+b \cdot \log (\mathrm{TSS})+c$,

where $R_{1}$ and $R_{2}$ represent the near-infrared band and red band of OLI, ETM+ and TM sensors. Parameters $a, b$ and $c$ refer to Fig. $4 a, b$ and c, respectively. The unit of TSS concentration is in milligrams per liter $\left(\mathrm{mgL}^{-1}\right)$.

Compared to the previous model developed by Ritchie and Cooper (1991), we improved the input with logarithmic transformation of bands and made full use of the different sensitivity of red and near-infrared bands to TSS concentrations that have been proved by many studies (Chen et al., 2015b; Feng et al., 2014; Wang et al., 2010; Hu et al., 2004). Compared to the MODIS-based models developed by Chen et al. (2011b) and Wang et al. (2010), the QRLTSS model established in this paper seems more complicated. The models (Chen et al., 2011b; Wang et al., 2010) are in linear or exponential form, belonging to a simple monotonic function that can cause unreliable estimation in some spectral ranges. Although the QRLTSS model developed in our study is similar to previous studies (Chen et al., 2009b, 2011a, $2015 b$ ), there are some differences among them. They are indeed all quadratic models, but the models developed by Chen et al. (2009b) and Chen et al. (2011a) are part of the curves. It is different from the form developed by Chen et al. (2015b) and this study, which are all complete quadratic curves. It should be noted that the partial quadratic curve has some limitations in estimating TSS concentration with the wide range. Some regions with lower or higher TSS concentration could not be retrieved accurately. In fact, TSS concentrations in the study area (Apalachicola Bay, USA) of Chen et al. (2009b) and Chen et al. (2011a) are not as high as TSS concentrations in the study areas of this paper and Chen et al. (2015b). The maximum TSS concentration in the previous studies was about $200 \mathrm{mgL}^{-1}$ (Chen et al., 2009b, 2011a), but the maximum TSS concentration was higher than $500 \mathrm{mg} \mathrm{L}^{-1}$ (Yangtze River estuary) for the previous study (Chen et al., 2015b) and this study. In addition, the study areas of Chen et al. (2015b) only include Xuwen Coral Reef National Nature Reserve, a less turbid region, and the Yangtze River estuary, an extremely turbid region, which might make the model developed by Chen et al. (2015b) perform worse in the middle of the quadratic curve than both ends of the quadratic curve. The QRLTSS model in this study is better in the continuity of calibration and validation data than Chen et al. (2015b). The reason is that the study areas of this paper include not only their regions (Chen et al., 2015b) but also the other three main estuarine regions in Guangdong Province (Moyangjiang River estuary, Pearl River estuary and Hanjiang River estuary). In general, the TSS concentrations in the three additional regions are higher than the those at Xuwen coast, but lower than those at the Yangtze River estuary. These data are a good supplement for a test of the robustness and accuracy of the model in the study.

It should be noted that a band value corresponds to two TSS concentration values based on the QRLTSS model (Eq. 4). We should make the unique choice when validating or retrieving TSS concentration by the model. Unfortunately, we had not been aware of this problem and did not solve it in our previous work (Wang et al., 2016). It meant that our previous results (Wang et al., 2016) were not complete. In this study, the TSS concentrations of the vertex corresponding to the three quadratic models based on Landsat OLI, ETM+ and TM sensors have been obtained through solving the Eq. (4) as follows. Firstly, the derivatives were calculated from Eq. (4) by calculus. Then, we can obtained the vertex point through solving the root of the derivative by the parameters (Fig. 4a-c for OLI: $-0.3575,1.1135,0.7162$; ETM+: $-0.2844,0.8578,0.8278$; TM: $-0.2821,0.8506,0.8295$ ). Finally, the vertex values were calculated. The vertex value for OLI is about $36.1 \mathrm{mg} \mathrm{L}^{-1}$. The vertex values for ETM+ and TM are about $32.2 \mathrm{mg} \mathrm{L}^{-1}$, which can be attributed to their almost-equal spectral band features (Table 4).

$$
\begin{aligned}
& \left(\frac{\log \left(R_{1}\right)}{\log \left(R_{2}\right)}\right)^{\prime}=2 a \cdot(\log (\mathrm{TSS}))+b \\
& \Rightarrow \log (\mathrm{TSS})=-\frac{b}{2 a}
\end{aligned}
$$




$$
\Rightarrow \mathrm{TSS}=10^{-\frac{b}{2 a}}
$$

For the QRLTSS model based on an OLI sensor, we found that the values of OLI red-band weighted reflectance of all validation data are lower than 0.032 when TSS concentrations are less than $36.1 \mathrm{mg} \mathrm{L}^{-1}$ (Fig. 5a, blue dots) apart from one exceptional datum (Fig. 5a, black dot). The reflectance is higher than 0.032 when TSS concentrations are higher than $36.1 \mathrm{mg} \mathrm{L}^{-1}$ (Fig. 5a, red dots). The QRLTSS models based on ETM+ and TM sensors have similar situations. But the values of TSS concentration and reflectance at the vertex are $32.2 \mathrm{mg} \mathrm{L}^{-1}$ and 0.031, shown in Fig. 5b (dots for ETM+ and triangles for TM). The findings are different from the result found in a MODIS-based model by Chen et al. (2015b). In a previous study (Chen et al., 2015b), the values of TSS concentration and reflectance of the MODIS red band at the vertex are $31 \mathrm{mg} \mathrm{L}^{-1}$ and 0.025 , respectively. We believe that the difference was caused by different spectral characteristics of satellite sensors (Table 4). This is also why multi-source satellite remote sensing has become more and more important in recent years. Monitoring TSS concentrations from multiple data sources could make full use of the advantages of all kinds of satellite sensors. According to the above analysis, TSS concentration can be retrieved by using Eq. (5) in the form of a positive squared root if the reflectance of red band is lower than 0.032 (OLI sensor) or 0.031 (ETM+ and TM sensors) and by using Eq. (5) in the form of a negative squared root if the reflectance of red band is greater than 0.032 (OLI sensor) or 0.031 (ETM+ and TM sensors), respectively.

$$
\log (\mathrm{TSS})=\frac{-b \pm \sqrt{b^{2}-4 a\left(c-\frac{\log \left(R_{1}\right)}{\log \left(R_{2}\right)}\right)}}{\left(b^{2}-4 a\left(c-\frac{\log \left(R_{1}\right)}{\log \left(R_{2}\right)}\right) \geq 0\right)}
$$

We validated the QRLTSS model based on the 35 in situ samples and the selection criteria (Eq. 5). The results indicated that the QRLTSS model has a better performance than the previous five TSS models, although the QRLTSS model explained about $72 \%$ of the TSS concentration variation only. The RMSEs and MREs of all validation data for QRLTSS model are $21.5 \mathrm{mgL}^{-1}$ and $27.2 \%$ for OLI (Fig. $4 \mathrm{a} 2$ ), $25 \mathrm{mgL}^{-1}$ and $32.5 \%$ for ETM+ (Fig. 4b2), and $24.9 \mathrm{mg} \mathrm{L}^{-1}$ and $31.5 \%$ for TM (Fig. $4 \mathrm{c} 2$ ), respectively. All of the simulated results from the QRLTSS model have higher validation accuracies than the best of the five previous TSS models (RMSE: $35.7 \mathrm{mg} \mathrm{L}^{-1}$, MRE: $39.4 \%$ ). According to the vertex location of the quadratic model, the wide range of validation data (TSS: $4.5-474 \mathrm{mg} \mathrm{L}^{-1}$ ) was divided into two parts of low (4.5-32.2 $\mathrm{m} \mathrm{L}^{-1}$, triangles in Figs. 3 and 4) and high (36.2-474 $\mathrm{mg} \mathrm{L}^{-1}$, squares in Figs. 3 and 4) TSS concentration for further validation. For the data of low TSS concentrations, the RMSEs and MREs of validation are
$3.5 \mathrm{mg} \mathrm{L}^{-1}$ and $31.1 \%$ for OLI, $4.6 \mathrm{mg} \mathrm{L}^{-1}$ and $38.3 \%$ for ETM+, and $4 \mathrm{mgL}^{-1}$ and $35.3 \%$ for TM. For the data of high TSS concentrations, the RMSEs and MREs of validation are $35.1 \mathrm{mgL}^{-1}$ and $20.7 \%$ for OLI, $40.7 \mathrm{mg} \mathrm{L}^{-1}$ and $20.3 \%$ for ETM+, and $40.6 \mathrm{mg} \mathrm{L}^{-1}$ and $25.1 \%$ for TM. The validation accuracies of the two parts are still better than the best of the previous five TSS models (RMSEs and MREs: $5.6 \mathrm{mg} \mathrm{L}^{-1}$ and $39.4 \%$ for the low-concentration part and $53.5 \mathrm{mg} \mathrm{L}^{-1}$ and $23.5 \%$ for the high-concentration part). Detailed information on the calibration and validation in Figs. 3 and 4 are shown in Table 3.

From Table 3 we could also find that the calibration and validation accuracy of the OLI-based QRLTSS model is a little higher than ETM+ and TM $\left(R^{2}: 0.7181\right.$ vs. 0.708 and 0.7079, RMSE: $21.5 \mathrm{mg} \mathrm{L}^{-1}$ vs. 25 and $24.9 \mathrm{mg} \mathrm{L}^{-1}$, MRE: $27.2 \%$ vs. 32.5 and $31.5 \%$ ). We attribute this mainly to the improvement of the Landsat OLI sensor's design. Especially for OLI band_5, the band of water vapor absorption at $825 \mathrm{~nm}$ was removed from the near-infrared band range, whose wavelength is $845-885 \mathrm{~nm}$ now (http://Landsat. usgs.gov/). However, the near-infrared band wavelengths of ETM+ and TM are 775-900 nm and 760-900 nm, respectively. In addition, the red-band wavelength of OLI is 630$680 \mathrm{~nm}$, and the correspondence of ETM+ and TM is 630$690 \mathrm{~nm}$. The small difference between ETM+ and TM sensors determines a small difference in QRLTSS model based on ETM+ and TM. The performance (red band and nearinfrared band) of different sensors and the vertexes of the QRLTSS model based on these sensors are shown in Table 4.

\subsection{Comparison of Landsat-measured reflectance with in situ reflectance}

In order to analyze the spatial and temporal variation of TSS concentrations in our study areas and further verify accuracy of QRLTSS model, the acquired Landsat imagery was used to calculate the TSS concentrations by the QRLTSS model described in Sect. 3.2 (Eq. 5). Atmospheric correction is critical for working with multi-scene imagery and empirical or semiempirical methods. Thus, the atmospheric correction accuracy of $6 \mathrm{~S}$ was calculated firstly based on the reflectance of synchronous in situ measurements, a total of 22 samples from three regions within a $2 \mathrm{~h}$ time window of satellite overpass (Bailey and Werdell. 2006; Chen et al., 2015; Zhang et al., 2014). Among them, 6 of the total 22 samples were collected from the Pearl River estuary on 2 November 2012, 9 samples were collected from the Hanjiang River estuary on 1 December 2013 and the other 7 samples were collected from the Moyangjiang River estuary on 6 December 2013. In deriving the reflectance comparison, the water-leaving radiances from Landsat imagery were averaged by window of $3 \times 3$ pixels of the location of the sample of the image. We then calculated RMSE and MRE of the reflectance result after atmospheric correction with in situ reflectance. RMSEs (MREs) of red and near-infrared bands are $0.0033(9.58 \%)$ and 0.00092 
Table 3. The comparison of calibration and validation accuracy of several of the best TSS retrieval models.

\begin{tabular}{lrrrr}
\hline Model form & Calibration $\left(R^{2}\right)$ & \multicolumn{2}{c}{ Validation (RMSE $\left.\left(\mathrm{mgL}^{-1}\right), \mathrm{MRE}\right)$} \\
\cline { 3 - 5 } & & Whole & Low range & High range \\
\cline { 3 - 5 } & & & & \\
Chen et al. (2014) & 0.7842 & $35.7,144.2 \%$ & $18.35,215.58 \%$ & $53.56,23.5 \%$ \\
Li et al. (2010) & 0.6167 & $69.3,45 \%$ & $5.66,52.6 \%$ & $113.48,32.1 \%$ \\
Zhang et al. (2014) & 0.5804 & $82.8,48 \%$ & $6.56,53.9 \%$ & $135.54,38.15 \%$ \\
Lathrop et al. (1991) & 0.6661 & $50.339 .4 \%$ & $6.12,44.6 \%$ & $82.09,30.57 \%$ \\
Ritchie and Cooper (1991) & 0.6983 & $68.7,41.3 \%$ & $7.24,44 \%$ & $112.32,36.6 \%$ \\
\hline This study OLI & 0.7181 & $21.5,27.2 \%$ & $3.5,31.1 \%$ & $35.1,20.7 \%$ \\
ETM+ & 0.708 & $25,32.5 \%$ & $4.6,38.3 \%$ & $40.7,20.3 \%$ \\
TM & 0.7079 & $24.9,31.5 \%$ & $4,35.3 \%$ & $40.6,25.1 \%$ \\
\hline \multicolumn{2}{c}{} & & &
\end{tabular}

Table 4. The performance of different sensors and the vertices of QRLTSS model based on these sensors.

\begin{tabular}{|c|c|c|c|c|}
\hline & $\mathrm{TM}$ & ETM+ & OLI & MODIS \\
\hline & $\begin{array}{r}\text { Red band, } \\
\text { near-infrared } \\
\text { band }\end{array}$ & $\begin{array}{r}\text { Red band, } \\
\text { near-infrared } \\
\text { band }\end{array}$ & $\begin{array}{r}\text { Red band, } \\
\text { near-infrared } \\
\text { band }\end{array}$ & $\begin{array}{r}\text { Red band, } \\
\text { near-infrared } \\
\text { band }\end{array}$ \\
\hline Wavelength (nm) & $\begin{array}{r}630-690 \\
760-900\end{array}$ & $\begin{array}{r}630-690 \\
775-900\end{array}$ & $\begin{array}{r}630-680 \\
845-885\end{array}$ & $\begin{array}{r}620-670, \\
841-874\end{array}$ \\
\hline Spatial resolution $(\mathrm{m})$ & 30 & 30 & 30 & 250 \\
\hline Radiometric resolution (bit) & 8 & 8 & 12 & 12 \\
\hline $\begin{array}{l}\text { Signal/noise (dB and } \\
\text { specified level of high) }\end{array}$ & 140,244 & 140,244 & 340,460 & 128,201 \\
\hline The vertex of quadratic model & $\begin{array}{r}0.031 \\
32.2 \mathrm{mg} \mathrm{L}^{-1} \\
\text { (this study) }\end{array}$ & $\begin{array}{r}0.031 \\
32.2 \mathrm{mg} \mathrm{L}^{-1} \\
\text { (this study) }\end{array}$ & $\begin{array}{r}0.032, \\
36.1 \mathrm{mg} \mathrm{L}^{-1} \\
\text { (this study) }\end{array}$ & $\begin{array}{r}0.025, \\
31 \mathrm{mgL}^{-1} \\
\text { (Chen et al., 2015b) }\end{array}$ \\
\hline
\end{tabular}

$(21.5 \%)$, respectively, which showed an acceptable accuracy. The results in Fig. 6 show that the 6S model was sufficiently stable and accurate for deriving the reflectance at visible and near-infrared bands from Landsat satellite data for the purpose of remote sensing applications in estuarine and coastal waters.

\subsection{Validation of QRLTSS model from Landsat imagery}

After atmospheric correction of 6S, the TSS concentrations of the Moyangjiang River estuary, part of the Pearl River estuary, and the Hanjiang River estuary were estimated from ETM+ or OLI imagery (Fig. 7). Figure 7a show the TSS concentrations in the Moyangjiang River estuary (11:00 LT) on 6 December 2013 with a large variation ranging from 0.557 to $203.9 \mathrm{mgL}^{-1}$. It is clear that the TSS concentrations are higher inside and outside of the Moyangiiang River estuary than the outer shelf area, especially in the downstream estuary, with a mean value of $154.2 \mathrm{mg} \mathrm{L}^{-1}$ (Fig. 7a). The region of high TSS concentrations in the Moyangjiang
River estuary looks lung-shaped. The outer shelf area has low TSS concentrations, where the TSS concentrations less than $35 \mathrm{~m} \mathrm{~L}^{-1}$ were frequently found and the maximum is not higher than $60 \mathrm{mgL}^{-1}$. So, there are sharp fronts that could be seen clearly between coastal area and outer shelf area. The TSS distribution in the Moyangjiang River estuary is mainly attributed to the interaction between tide and runoff. In this study, the remote sensing imagery covering the Moyangjiang River estuary was obtained at 11:00 LT in the morning when the tide had begun to ebb and runoff with large amounts of sediment flowed into the South China Sea.

Different from TSS concentrations in the Moyangjiang River estuary, the TSS concentrations in eastern Zhuhai and Macao and Hong Kong coastal water bodies have much lower TSS values, with a mean value of $12 \mathrm{mg} \mathrm{L}^{-1}$ (Fig. 7b, blank areas without synchronous image). There was a significant decreasing trend of TSS concentration from the northwest to southeast of the Pearl River estuary. It was mainly due to the interaction between runoff (flowing southwest) and tide (flowing northwest). The maximum TSS concentration was about $29 \mathrm{mgL}^{-1}$. The reason why the water bod- 
ies in the outer Lingding Bay of the Pearl River estuary had a low-level TSS concentration was probably because of strong management protection and less human activity. Most parts of the eastern Zhuhai water bodies have belonged to the Pearl River estuary Chinese White Dolphin National Nature Reserve (NNR) since 2003 (http://www.gdofa.gov.cn/). The NNR has an area of about $460 \mathrm{~km}^{2}$ located between latitudes $21.18-22.4^{\circ} \mathrm{N}$ and longitudes $113.66-113.87^{\circ} \mathrm{E}$, shown in Fig. 7b (region with black dotted line). The low TSS concentrations in this region confirm the protection effect of the Chinese White Dolphin NNR.

Compared to the Moyangjiang River estuary and eastern Zhuhai and Macao coastal water bodies, the TSS concentrations in the Hanjiang River estuary had wider variables, ranging from 0.295 to $370.4 \mathrm{mg} \mathrm{L}^{-1}$. The water bodies with high TSS concentrations in this region were mainly in two zones where the sharp fronts of TSS were clearly visible (Fig. 7c, zones 1 and 2). The TSS concentrations in zone 1 were almost higher than $100 \mathrm{mg} \mathrm{L}^{-1}$, with a maximum value of $370.4 \mathrm{mg} \mathrm{L}^{-1}$ and a mean value of $167.91 \mathrm{mg} \mathrm{L}^{-1}$. For zone 2 , the TSS concentrations mostly ranged from 20 to $110 \mathrm{mg} \mathrm{L}^{-1}$, and the maximum and mean value were 127.14 and $61.57 \mathrm{mgL}^{-1}$, respectively. The results also showed that the turbid river runoff flows into South China Sea along east coast of Dahao District, Shantou City. The high TSS concentrations in this region were caused by different factors. In zone 1 at the opposite bank of Dahao District, Shantou, it was mainly caused by the runoff of the Xixi waterway in the Hanjiang River and flow guiding line (dam, solid black line in Figs. 1e and 7c) connected to Longhu District, Shantou City. While in zone 2, the high TSS concentrations resulted from the interaction between tide current and runoff, which is the potential location of estuarine barrier bar. The TSS concentrations in an estuary of the Xinjinhe waterway in the Hanjiang River were less than $50 \mathrm{mg} \mathrm{L}^{-1}$. The results are similar to the results of Ding and Xu (2007), which showed TSS concentrations ranged from 0.1 to $300 \mathrm{mg} \mathrm{L}^{-1}$ in the Hanjiang River estuary.

The accuracy of TSS concentration estimated from Landsat imagery of two OLIs and one ETM+ was further validated with 22 quasi synchronous in situ samples that were collected from the Pearl River estuary, Hanjiang River estuary and Moyangjiang River estuary. The validation accuracy is shown in Fig. 7d. The RMSE and MRE of comparison between 22 field TSS concentrations $\left(7-160 \mathrm{mg} \mathrm{L}^{-1}\right)$ and Landsat satellite inversion are $11.06 \mathrm{mg} \mathrm{L}^{-1}$ and $24.1 \%$, respectively. In addition, the RMSEs and MREs of validation for the low range $\left(7-28.2 \mathrm{mg} \mathrm{L}^{-1}, N=18\right)$ and the high range (37-160 $\left.\mathrm{mg} \mathrm{L}^{-1}, N=4\right)$ of TSS concentrations in the three estuaries are $3.75 \mathrm{mg} \mathrm{L}^{-1}$ and $22 \%$ and $24.69 \mathrm{mg} \mathrm{L}^{-1}$ and $33.2 \%$, respectively. These results indicate that the QRLTSS model is applicable to the mapping of TSS in all of three estuaries from Landsat imagery.

\subsection{Further validation of QRLTSS model from EO-1 Hyperion imagery}

We were fortunate to acquire EO-1 Hyperion imagery at 10:33 LT with 13 synchronous samples (Fig. 1d, 10 sites with symbol of triangles and 3 sites with symbol of dots. TSS: 106-220.7 $\mathrm{mg} \mathrm{L}^{-1}$ ) on 21 December 2006 covering part of the Pearl River estuary from northeast to southwest in the Lingding Bay. The dataset gives us an opportunity to further validate the accuracy of the QRLTSS model. After similar pre-processing steps with Landsat imagery, the EO-1 Hyperion imagery was also used to retrieve TSS concentrations using the QRLTSS model. The results of TSS concentration mapping and validation accuracy are shown in Fig. 8.

The TSS concentration mapping from Hyperion image on 21 December 2006 ranged from 1.79 to $361.6 \mathrm{mg} \mathrm{L}^{-1}$, with a mean value of $124.4 \mathrm{mg} \mathrm{L}^{-1}$ (Fig. 8a). The mapping results of TSS showed large variation from northeast to southwest in the Pearl River estuary. The areas of low TSS concentration were detected near the southwest of Lingding Bay (mostly in the NNR, Fig. 7b) and in deep channels (east channel and west channel, Fig. 8a) of Lingding Bay. The areas of high TSS concentration were in accordance with the outlets of different waterways (Humen, Jiaomen, Hongqimen and Hengmen) of the Pearl River estuary frequently or the foreshores, which indicate that it is the maximum turbidity zones of the estuary. The 13 synchronous samples (TSS: 106-220.7 $\mathrm{mg} \mathrm{L}^{-1}$ ) were mostly collected from the northern zone of high TSS concentrations (Fig. 1d). Comparisons of accuracy validation between in situ and Hyperion imagery inversed TSS concentrations are produced in Fig. $8 \mathrm{~b}$. The RMSE and MRE of comparison are $26.66 \mathrm{mg} \mathrm{L}^{-1}$ and $12.6 \%$, respectively. It showed that the QRLTSS model also worked well in area of high TSS concentrations from Hyperion mapping result of the Pearl River estuary.

Based on the evaluation and analysis of all the above results (Figs. 3, 4, 7 and 8, Tables 3 and 4), we conclude that the QRLTSS model has the advantage for quantitative inversion of TSS concentrations with a high dynamic range in estuaries and coasts. These results explained the usability of QRLTSS model by the validation of multi-spectral Landsat OLI, ETM+ and hyperspectral EO-1 Hyperion imagery compared to our previous work (Wang et al., 2016).

\section{Summary and conclusions}

This study developed a QRLTSS model with high adaptability and robustness for estimating wide TSS concentration variables of estuaries and coasts from Landsat imagery (TSS: $4.3-577.2 \mathrm{mg} \mathrm{L}^{-1}, R^{2}: \sim 0.72, N=84, P$ value $\left.<0.001\right)$. The QRLTSS model got a reasonable validation accuracy by the independent in situ samples (TSS: $4.5-474 \mathrm{mg} \mathrm{L}^{-1}$, RMSE $\leq 25 \mathrm{mgL}^{-1}, N=35$ ). Compared to the 22 previous Landsat-based models (Table 2), the QRLTSS model has 
better performance (Table 3). In addition, we found that the QRLTSS model based on the bands of OLI showed a higher accuracy than those based on bands of ETM+ and TM (Table 3 and Fig. 4), which can be explained by the adjusted band design of OLI sensor in reducing the effect of water vapor absorption compared to ETM+ and TM sensors (Table 4).

The QRLTSS model showed good performance when applied to estimate TSS concentrations from Landsat OLI and ETM+ imagery (Fig. 7). The RMSEs and MREs of validation from Landsat imagery (Moyangjiang River estuary, 6 December 2013; part of the Pearl River estuary, 2 November 2012; and Hanjiang River estuary, 1 December 2013) are $11.06 \mathrm{mg} \mathrm{L}^{-1}$ and $24.1 \%$ for the whole range (7-160 $\left.\mathrm{mg} \mathrm{L}^{-1}\right), 3.75 \mathrm{mg} \mathrm{L}^{-1}$ and $22 \%$ for the low range (7-28.2 $\mathrm{mg} \mathrm{L}^{-1}$ ), and $24.69 \mathrm{mg} \mathrm{L}^{-1}$ and $33.2 \%$ for the high range (37-160 $\mathrm{m} \mathrm{L}^{-1}$ ) of TSS concentrations, respectively. Besides, the high validation accuracy of TSS mapping from Hyperion imagery of the Pearl River estuary (21 December 2006) with in situ data (106-220.7 $\left.\mathrm{mg} \mathrm{L}^{-1}\right)$ using the QRLTSS model had also been obtained (Fig. 8, RMSE: $26.66 \mathrm{mg} \mathrm{L}^{-1}$, MRE: $12.6 \%$ ).

Landsat imagery could be one of the best choices in terms of the availability of data sources for remote sensing of TSS in estuaries and coasts, considering the spatial resolution and acquirement of long time series (30 m Landsat TM, ETM+ and OLI beginning in 1982, $80 \mathrm{~m}$ MSS, Multispectral Scanner System, since 1972). The research shows that the QRLTSS model can quantify the TSS concentration variation of estuaries and coasts by Landsat series of imagery with applicable accuracies $\left(R^{2}: 0.71-0.72,30 \mathrm{~m}\right)$, which can be compared to the accuracies of previous Landsat-based studies ( $R^{2}: 0.67-0.92,30 \mathrm{~m}$, Chen et al., 2014; Nas et al., 2010) and MODIS-based studies $\left(R^{2}: 0.61-0.86,250 \mathrm{~m}\right.$, Chen et al., 2011a; Wang et al., 2010). The TSS concentrations at the vertex of the QRLTSS model based on Landsat sensors are different from MODIS (Table 4). Based on the vertex of QRLTSS model, we proposed a threshold (corresponding to the vertex of quadratic function) of red-band reflectance (Fig. 5, OLI: 0.032, ETM+ and TM: 0.031) which can be used to divide the quadratic function for solving the QRLTSS model under two kinds of squared roots (Table 4).

For a lot of medium- and high-resolution remote sensing sensors similar to Landsat series satellites, such as HJ-1 A and B, LISS, CBERS, ASTER, ALOS, RapidEye, Kanopus$\mathrm{V}$, and GF, we deduce that there is potential to optimize the QRLTSS model for mapping the wide range of TSS concentrations of estuaries and coasts from multi-source satellite remote sensing. It will be beneficial to the understanding of the spatial and temporal variation of TSS concentrations on regional and global scales and provide great help in establishing regional or unified TSS remote sensing models of estuaries and coasts throughout the world.
Code and data availability. The LEDAPS code used for atmospheric correction is freely available at https://github.com/ usgs-eros/espa-surface-reflectance (USGS, 2004) and all the remote sensing imagery can be downloaded freely at https://glovis. usgs.gov/ (USGS, 1982; NASA, 2001).

Competing interests. The authors declare that they have no conflict of interest.

Acknowledgements. This research was supported by the Technology Transformation Project of Zhongshan City, Guangdong Academy of Sciences (2016G1FC0017), Science and Technology Plan Project of Guangdong Province (2016A020223011, 2015B070701020, 2014A020216027), the Water Conservancy Science and Technology Innovation Project (2011-20), and GDAS' Special Project of Science and Technology Development (2017GDASCX-0101). The authors would like to thank Hongqiu Li for sampling help in The Hydrographic Office of Hydrology Station in Zhanjiang, and Haishan Li for water quality analysis of partial samples in Guangzhou Panyu Water Supply (Group) Co., Ltd, Guangzhou, Guangdong Province. Thanks are also given to USGS for providing the Landsat imagery and the International Scientific Data Service Platform at the Computer Network Information Center at the Chinese Academy of Sciences for providing gap-filled ETM+ SLC-free data (http://datamirror.csdb.cn). Authors appreciate the constructive suggestions from reviewers and editors that helped improve this paper.

Edited by: Bethanna Jackson

Reviewed by: Otavio Montanher and one anonymous referee

\section{References}

Bailey, S. W. and Werdell, P. J.: A multi-sensor approach for the on-orbit validation of ocean color satellite data products, Remote Sens. Environ., 102, 12-23, https://doi.org/10.1016/j.rse.2006.01.015, 2006.

Binding, C. E., Jerome, J. H., Bukata, R. P., and Booty, W. G.: Suspended particulate matter in Lake Erie derived from MODIS aquatic colour imagery, Int. J. Remote Sens., 31, 5239-5255, https://doi.org/10.1080/01431160903302973, 2010.

Binding, C. E., Greenberg, T. A., and Bukata, R. P.: An Analysis of MODIS-Derived Algal and Mineral Turbidity in Lake Erie, J. Great Lakes Res., 38, 107-116, https://doi.org/10.1016/j.jglr.2011.12.003, 2012.

Caballero, I., Morris, E. P., Ruiz, J., and Navarro, G.: Assessment of suspended solids in the Guadalquivir estuary using new DEIMOS-1 medium spatial resolution imagery, Remote Sens. Environ., 146, 148-158, https://doi.org/10.1016/j.rse.2013.08.047, 2014.

Chander, G., Markham, B. L., and Helder, D. L.: Summary of current radiometric calibration coefficients for Landsat MSS, TM, ETM+, and EO-1 ALI sensors, Remote Sens. Environ., 113, 893-903, https://doi.org/10.1016/j.rse.2009.01.007, 2009.

Chen, S., Fang, L., Zhang, L., and Li, D.: Remote sensing of turbidity in seawater intrusion reaches of Pearl River 
estuary: a case study in Modaomen waterway of Pearl River estuary China, Estuar. Coast. Shelf Sci., 82, 119-127, https://doi.org/10.1016/j.ecss.2009.01.003, 2009a.

Chen, S., Huang, W., Wang, H., and Li, D.: Remote sensing assessment of sediment re-suspension during Hurricane Frances in Apalachicola Bay, USA, Remote Sens. Environ., 113, 26702681, https://doi.org/10.1016/j.rse.2009.08.005, 2009b.

Chen, S., Huang, W. R., Chen, W. Q., and Chen, X. Z.: An enhanced MODIS remote sensing model for detecting rainfall effects on sediment plume in the coastal waters of Apalachicola Bay, Marine Environ. Res., 72, 265-272, https://doi.org/10.1016/j.marenvres.2011.09.014, 2011a.

Chen, S., Huang, W. R., Chen, W. Q., and Wang, H. Q.: Remote sensing analysis of rainstorm effects on sediment concentrations in Apalachicola Bay, USA. Ecol. Inform., 6, 147-155, https://doi.org/10.1016/j.ecoinf.2010.12.001, 2011 b.

Chen, Y., Kong, J., Sun, X., Du, D., and Cheng, P.: Retrieval of sea surface suspended sediment concentration in Bohai Gulf Offshore area based on semi-analysis model, Geogr. Geo-Inform. Sci., 30, 33-36, https://doi.org/10.3969/j.issn.16720504.2014.03.008, 2014.

Chen, J., Quan, W., Cui, T., and Song, Q.: Estimation of total suspended matter concentration from MODIS data using a neural network model in the China eastern coastal zone, Estuar. Coast. Shelf S., 155, 104-113, https://doi.org/10.1016/j.ecss.2015.01.018, 2015a.

Chen, S., Han, L., Chen, X., Li, D., Sun, L., and Li, Y.: Estimating wide range Total Suspended Solids concentrations from MODIS 250-m imageries: an improved method, ISPRS J. Photogrammetry Remote Sensing, 99, 58-69, https://doi.org/10.1016/j.isprsjprs.2014.10.006, 2015 b.

Dekkera, A. G., Vosb, R. J., and Petersb, S. W. M.: Comparison of remote sensing data, model results and in-situ data for total suspended matter žTSM/in the southern Frisian lakes, Sci. Total Environ., 268, 197-214, https://doi.org/10.1016/S00489697(00)00679-3, 2001.

Ding, X. and $\mathrm{Xu}, \mathrm{X}$. : A remote sensing analysis of characteristics of Suspended sediments movement in Hanjiang estuary, Remote Sensing Land Resour., 3, 71-74, https://doi.org/10.3969/j.issn.1001-070X.2007.03.016, 2007.

Doxaran, D., Froidefond, J. M., Lavender, S., and Castaing, P.: Spectral signature of highly turbid waters Application with SPOT data to quantify suspended particulate matter concentrations, Remote Sens. Environ., 81, 149-161, https://doi.org/10.1016/S0034-4257(01)00341-8, 2002.

Doxaran, D., Froidefond, J. M., and Castaing, P.: Remote-sensing reflectance of turbid sediment-dominated waters, Reduction of sediment type variations and changing illumination conditions effects by use of reflectance ratios, Appl. Opt., 42, 2623-2634, https://doi.org/10.1364/AO.42.002623, 2003.

Feng, M., Sexton, J. O., Huang, C., Masek, J. G., Vermote, E. F., Gao, F., Narasimhan, R., Channan, S., Wolfe, R. E., and Townshend, J. R.: Global surface reflectance products from Landsat: assessment using coincident MODIS observations, Remote Sens. Environ., 134, 276-293, 2013.

Feng, L., Hu, C., Chen, X., and Song, Q.: Influence of the Three Gorges Dam on total suspended matters in the Yangtze Estuary and its adjacent coastal waters: observa- tions from MODIS, Remote Sens. Environ., 140, 779-788, https://doi.org/10.1016/j.rse.2013.10.002, 2014.

Fraser, R. N.: Multispectral remote sensing of turbidity among Nebraska Sand Hills lakes, Int. J. Remote Sens., 19, 3011-3016, https://doi.org/10.1016/j.rse.2013.02.031, 1998.

Giardino, C., Brando, V. E., Dekker, A. G., Strömbeck, N., and Candiani, G.: Assessment of water quality in Lake Garda (Italy) using Hyperion. Remote Sens. Environ., 109, 183-195, https://doi.org/10.1016/j.rse.2006.12.017, 2007.

Giardino, C., Bresciani, M., Valentini, E., Gasperini, L., Bolpagni, R., and Brando, V. E.: Airborne hyperspectral data to assess suspended particulate matter and aquatic vegetation in a shallow and turbid lake, Remote Sens. Environ., 157, 48-57, https://doi.org/10.1016/j.rse.2014.04.034, 2015.

Gordon, H. R. and Wang, M.: Retrieval of water-leaving radiance and aerosol optical thickness over the oceans with SeaWiFS: a preliminary algorithm, Appl. Opt., 33, 443-452, https://doi.org/10.1364/AO.33.000443, 1994.

Hedley, J. D., Harborne, A. R., and Mumby, P. J.: Simple and robust removal of sun glint for mapping shallowwater benthos, Int. J. Remote Sens., 26, 2107-2112, https://doi.org/10.1080/01431160500034086, 2005.

Hochberg, E. J., Andréfouët, S., Tyler, M. R.: Sea surface correction of high spatial resolution IKONOS images to improve bottom mapping in near-shore environments, IEEE T. Geosci. Remote, 41, 1724-1729, https://doi.org/10.1109/TGRS.2003.815408, 2003.

Hsu, S.-C., and Lin, F. J.: Elemental characteristics of surface suspended particulates off the Changjiang estuary during the 1998 flood, J. Marine Syst., 81, 323-334, https://doi.org/10.1016/j.jmarsys.2010.03.001, 2010.

Hu, C., Chen, Z., Clayton, T. D., Swarzenski, P., Brock, J. C., and Muller-Karger, F. E.: Assessment of estuarine water-quality indicators using MODIS medium-resolution bands: initial results from Tampa Bay, FL, Remote Sens. Environ., 93, 423-441, https://doi.org/10.1016/j.rse.2004.08.007, 2004.

Islam, M. R., Yamaguchi, Y., and Ogawa, K.: Suspended sediment in the Ganges and Brahmaputra Rivers in Bangladesh: observation from TM and AVHRR data, Hydrol. Process., 15, 493-509, https://doi.org/10.1002/hyp.165, 2001.

Jiang, H., Feng, M., Zhu, Y., Lu, N., Huang, J., and Xiao, T.: An automated method for extracting rivers and lakes from Landsat imagery, Remote Sensing, 6, 5067-5089, https://doi.org/10.3390/rs6065067, 2014.

Ju, J., Roy, D. P., Vermote, E., Masek, J., and Kovalskyy, V.: Continental-scale validation of MODIS-based and LEDAPS Landsat ETM+ atmospheric correction methods, Remote Sens. Environ., 122, 175-184, https://doi.org/10.1016/j.rse.2011.12.025, 2012.

Kaufman, Y. J. and Tanré, D.: Strategy for direct and indirect methods for correcting the aerosol effect on remote sensing: from AVHRR to EOS-MODIS, Remote Sens. Environ., 55, 65-79, https://doi.org/10.1016/0034-4257(95)00193-X, 1996.

Keiner, L. E. and Yan, X. H.: A neural network model for estimating sea surface chlorophyll and sediments from thematic mapper imagery, Remote Sens. Environ., 66, 153-165, https://doi.org/10.1016/S0034-4257(98)00054-6, 1998.

Lathrop, R. G., Lillesand, T. M., and Yandell, B. S.: Testing the utility of simple multi-date Thematic Mapper calibration algorithms 
for monitoring turbid inland waters, Int. J. Remote Sens., 12, 2045-2063, https://doi.org/10.1080/01431169108955235, 1991.

Li, J., Shu, G., and Yaping, W.: Delineating suspended sediment concentration patterns in surface waters of the Changjiang Estuary by remote sensing analysis, Acta Oceanol. Sinica, 29, 38-47, https://doi.org/10.1007/s13131-010-0054-7, 2010.

Liu, Y., Islam, M. A., and Gao, J.: Quantification of shallow water quality parameters by means of remote sensing, Prog. Phys. Geog., 27, 24-43, https://doi.org/10.1191/0309133303pp357ra, 2003.

Lu, C., Lv, H., and Li, Y.: Backscattering properties and parametric model of Taihu Lake based on spectral classification, J. Remote Sensing, 16, 417-434, 2012.

Ma, D. and Wang, J.: Evaluation on potential ecological risk of sediment pollution in main estuaries of China, China Environ. Sci., 23, 521-525, 2003.

Ma, R., Tang, J., Duan, H., and Pan, D.: Progress in lake water color remote sensing, J. Lake Sci., 21, 143-158, https://doi.org/10.18307/2009.0201, 2009.

Ma, R., Duan, H., Tang, J., and Chen, Z.: Remote Sensing of Lake Water Environment, Science Press, Beijing, 2010.

Maiersperger, T. K., Scaramuzza, P. L., Leigh, L., Shrestha, S., Gallo, K. P., Jenkerson, C. B., and Dwyer, J. L.: Characterizing LEDAPS surface reflectance products by comparisons with AERONET, field spectrometer, and MODIS data, Remote Sens. Environ., 136, 1-13, https://doi.org/10.1016/j.rse.2013.04.007, 2013.

Masek, J. G., Vermote, E. F., Saleous, N. E., Wolfe, R., Hall, F. G., Huemmrich, K. F., Gao, F., Kutler, J., and Lim, T.-K.: A Landsat surface reflectance dataset for North America, 1990-2000, IEEE Geosci. Remote S., 3, 68-72, https://doi.org/10.1109/LGRS.2005.857030, 2006.

May, C. L., Koseff, J. R., Lucas, L. V., Cloern, J. E., and Schoellhamer, D. H.: Effects of spatial and temporal variability of turbidity on phytoplankton blooms, Mar. Ecol. Prog. Ser., 254, 111128, https://doi.org/10.3354/meps254111, 2003.

Mei, A., Peng, W., Qin, Q., and Liu, H.: Introduction to Remote Sensing, Higher Eduction Press, Beijing, 2001.

Montanher, O. C., Novo, E. M. L. M., Barbosa, C. C. F., Renno, C. D., and Silva, T. S. F.: Empirical models for estimating the suspended sediment concentration in Amazonian white water rivers using Landsat/TM, Int. J. Appl. Earth Obs., 29, 67-77, https://doi.org/10.1016/j.jag.2014.01.001, 2014.

Nas, B., Ekercin, S., Karabörk, H., Berktay, A., and Mulla, D. J.: An application of Landsat-5TM Image data for water quality mapping in Lake Beysehir, Turkey, Water Air Soil Pollut., 212, 183197, https://doi.org/10.1007/s11270-010-0331-2, 2010.

NASA (National Aeronautics and Space Administration): The EO-1 Extended Mission, available at: http://eo1.usgs.gov (last access: 22 February 2017), 2001.

Nechad, B., Ruddick, K., and Park, Y.: Calibration and validation of a generic multisensor algorithm for mapping of total suspended matter in turbid waters, Remote Sens. Environ., 114, 854-866, https://doi.org/10.1016/j.rse.2009.11.022, 2010.

Olmanson, L. G., Brezonik, P. L., and Bauer, M. E.: Airborne hyperspectral remote sensing to assess spatial distribution of water quality characteristics in large rivers-The Mississippi River and its tributaries in Minnesota, Remote Sens. Environ., 130, 254 265, https://doi.org/10.1016/j.rse.2012.11.023, 2013.
Oyama, Y., Matsushita, B., Fukushima, T., Matsushige, K., and Imai, A.: Application of spectral decomposition algorithm for mapping water quality in a turbid lake (Lake Kasumigaura, Japan) from Landsat TM data, ISPRS J. Photogramm., 64, 7385, https://doi.org/10.1016/j.isprsjprs.2008.04.005, 2009.

Pozdnyakov, D., Shuchman, R., Korosov, A., and Hatt, C.: Operational algorithm for the retrieval of water quality in the Great Lakes, Remote Sens. Environ., 97, 352-370, https://doi.org/10.1016/j.rse.2005.04.018, 2005.

Raharimahefa, T. and Kusky, T. M.: Environmental monitoring of Bombetoka Bay and the Betsiboka Estuary, Madagascar, using multi-temporal satellite data, J. Earth Sci., 21, 210-226, https://doi.org/10.1007/s12583-010-0019-y, 2010.

Rao, K. H. V. D., Singh, A. K., and Roy, P. S.: Study of morphology and suspended sediment of Bhopal Upper Lake using spatial simulation technique and remote sensing data, Indian Soc. Remote Sensing, 37, 433-441, https://doi.org/10.1007/s12524-0090034-6, 2009.

Ritchie, J. C. and Cooper, C. M.: An algorithm for estimating surface suspended sediment concentrations with Landsat MSS digital data, Water Resour. Bull., 27, 373-379, https://doi.org/10.1111/j.1752-1688.1991.tb01436.x, 1991.

Ritchie, J. C. and Zimba, P. V.: Estimation of Suspended Sediment and Algae in Water Bodies, vol. 62, Part 5. Remote Sensing, published online, Wiley and Sons, New Jersey, USA, https://doi.org/10.1002/0470848944.hsa066, 2006.

Shen, Z., Zhou, S., and Pei, S.: Transfer and transport of phosphorus and silica in the turbidity maximum zone of the Changjiang estuary, Estuar. Coast. Shelf S., 78, 481-492, https://doi.org/10.1016/j.ecss.2008.01.010, 2008.

Shen, F., Salama, M. S., Zhou, Y.-X., Li, J.-F., Su, Z., and Kuang, D.-B.: Remote-sensing reflectance characteristics of highly turbid estuarine waters-a comparative experiment of the Yangtze River and the Yellow River, Int. J. Remote Sens., 31, 2639-2654, https://doi.org/10.1080/01431160903085610, 2010.

Sipelgas, L., Ossipova, V., Raudsepp, U., and Lindfors, A.: A biooptical model for the calculation of suspended matter concentration form MODIS data in Pakri Bay, the gulf of Finland, Boreal Environ. Res., 14, 415-426, 2009.

Song, K., Wang, Z., Blackwell, J., Zhang, B., Li, F., Zhang, Y., and Jiang, G.: Water quality monitoring using Landsat Themate Mapper data with empirical algorithms in Chagan Lake, China, J. Appl. Remote Sens., 5, 053506-053516, https://doi.org/10.1117/1.3559497, 2011.

Tang, J., Tian, G., Wang, X., Wang, X., and Song, Q.: The methods of water spectra measurement and analysis: above-water method, J. Remote Sens., 8, 37-44, 2004a.

Tang, J., Wang, X., Song, Q., Li, T., Chen, J., Huang, H., and Ren, J.: The statistic inversion algorithms of water constituents for the Huanghai Sea and the East China Sea, Acta Oceanol. Sin., 23, 617-626, 2004b.

Tang, W., Ma, C., Niu, S., Wang, X., Song, Q., and Ding, J.: Quantitative inversion of the water body composition based on CBERS02 datas, Sci. China Inform. Sci., 35, 156-170, 2005.

Topliss, B. J., Almos, C. L., and Hill, P. R.: Algorithms for remote sensing of high concentration, inorganic suspended sediment, Int. J. Remote Sens., 11, 947-966, https://doi.org/10.1080/01431169008955069, 1990. 
USGS (US Geological Survey) Land Remote Sensing (LRS) Program: The Landsat project, available at: https://landsat.usgs.gov (last access: 30 April 2017), 1982.

USGS (US Geological Survey) Earth Resources Observation and Science (EROS) Land Satellite Data Systems (LSDS) Science Research and Development (LSRD) Project: The surface reflectance project contains application source code for producing surface reflectance products, available at: https://github.com/ usgs-eros/espa-surface-reflectance (last access: 16 November 2017), 2004.

Vermote, E. F., Tanr'e, D., Deuz'e, J. L., Herman, M., and Morcrette, J.-J.: Second simulation of the satellite signal in the solar spectrum, 6S: an overview, IEEE T. Geosci. Remote S., 35, 675686, https://doi.org/10.1109/36.581987, 1997.

Vidot, J. and Santer, R.: Atmospheric correction for inland watersapplication to SeaWiFS, Int. J. Remote Sens., 26, 3663-3682, https://doi.org/10.1080/01431160500034029, 2005.

Volpe, V., Silvestri, S., and Marani, M.: Remote sensing retrieval of suspended sediment concentration in shallow waters, Remote Sens. Environ., 115, 44-54, https://doi.org/10.1016/j.rse.2010.07.013, 2011.

Wang, L., Zhao, H., Song, C., Yuan, J., and Yu, H.: Coastal geomorphic evolut ion at the Denglou Cape, the Leizhou Peninsula, Acta Oceanol. Sin., 21, 597-611, 2002.

Wang, H., Hladik, C. M., Huang, W., Milla, K., Edmiston, L., Harwell, M. A., and Schalles, J. F.: Detecting the spatial and temporal variability of chlorophylla concentration and total suspended solids in Apalachicola Bay, Florida using MODIS imagery, Int. J. Remote Sens., 31, 439-453, https://doi.org/10.1080/01431160902893485, 2010.
Wang, C., Li, D., Wang, D., Chen, S., and Liu, W.: A total suspended sediment retrieval model for multiple estuaries and coasts by Landsat imageries, 2016 4th International Workshop on Earth Observation and Remote Sensing Applications, Guangzhou, China, 4-6 July 2016, New York, USA, IEEE, https://doi.org/10.1109/EORSA.2016.7552785, 2016.

Wu, G., Cui, L., Duan, H., Fei, T., and Liu, Y.: An approach for developing Landsat-5 TM-based retrieval models of suspended particulate matter concentration with the assistance of MODIS, ISPRS J. Photogramm., 85, 84-92, https://doi.org/10.1016/j.isprsjprs.2013.08.009, 2013.

Zhang, Y., Zhang, B., Wang, X., Li, J., Feng, S., Zhao, Q., Liu, M., and Qin, B.: A study of absorption characteristics of chromophoric dissolved organic matter and particles in Lake Taihu, China, Hydrobiologia, 592, 105-120, https://doi.org/10.1007/s10750-007-0724-4, 2007.

Zhang, M., Dong, Q., Cui, T., Xue, C., and Zhang, S.: Suspended sediment monitoring and assessment for Yellow River estuary from Landsat TM and ETM+ imagery, Remote Sens. Environ., 146, 136-147, https://doi.org/10.1016/j.rse.2013.09.033, 2014.

Zhang, Y., Zhang, Y., Zha, Y., Shi, K., Zhou, Y., and Wang, M.: Remote sensing estimation of total suspended matter concentration in Xin'anjiang Reservoir using Landsat 8 data, Environ. Sci., 36, 56-63, https://doi.org/10.13227/j.hjkx.2015.01.008, 2015.

Zhao, H., Chen, Q., Walker, N. D., Zheng, Q., and Macintyre, H. L.: A study of sediment transport in a shallow estuary using MODIS imagery and particle tracking simulation, Int. J. Remote Sens., 32, 6653-6671, https://doi.org/10.1080/01431161.2010.512938, 2011. 